\title{
DESIGN OPTIMIZATION OF BETA- AND PHOTOVOLTAIC CONVERSION DEVICES
}

\author{
R. Wlchner, A. Blun, E. Fiacher-Colbrie and H. Chau
}

January 8, 1976

Prepared for U.S. Energy Research \& Develop nent

Administration under contract No. W-7405-Eng-48



s 


\section{NOTKE}

$\because$

"This feport was prepared as in aceount of work eponiored by the Urited Stakes Government. Noithir the Uniled Statre not the Urited States Enesy Resairch L Development Adminatration. wot any of their employees, nor any of thel contractors subcoatractors, or their employees makea tay warienty express or implied, of anumes uny tetal liability or respondibility for the ecuracy, completenes or usaruifiess of any information, spparatus, product or process dlacloned, of represents that its use would not intriss privutedyowined rights."

Printed in the United States of Amerien Avallable from

National Technical Information Service

U.S. Department of Coinmerce

5285 Port Royal Road

Springfield, VA 22161

Price: Printed Copy $\$$; Microfiche \$2.25

\begin{tabular}{|c|c|c|c|}
\hline Pus Rine & Price & Pape Rance & Prics \\
\hline $001-025$ & $\$ 3.50$ & $326-350$ & 10.00 \\
\hline $026-050$ & 4.00 & $351-375$ & 10.50 \\
\hline $051-075$ & 4.50 & $376-400$ & 10.75 \\
\hline $076-100$ & 5.00 & $401-425$ & 11.00 \\
\hline $101-125$ & 5.25 & $426-450$ & 11.75 \\
\hline $126-150$ & 5.50 & $451-475$ & 12.00 \\
\hline $151-175$ & 6.00 & $476-500$ & 12.50 \\
\hline $176-200$ & 7.50 & $501-525$ & 12.75 \\
\hline $201-225$ & 7.75 & $526-550$ & 13.00 \\
\hline $226-250$ & 8.00 & $551-575$ & 13.50 \\
\hline $251-275$ & 9.00 & $576-600$ & 13.75 \\
\hline $276-300$ & 9.25 & $601-u p$ & * \\
\hline $301-325$ & 9.75 & & \\
\hline
\end{tabular}

Atd $\$ 2.50$ for each ndilitionel 190 page increment from 601 to 1,000 pases: ad 150 for each additioval 100 pago increment over 1,000 pages. 


\section{니 \\ LAWRENCE LNERWOAE LABOAATORY

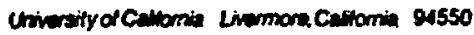

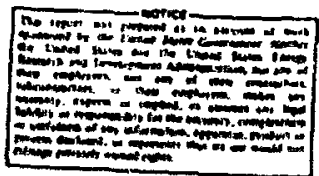

UCRL -51993

\section{DESIGN OPTIMIZATION OF BETA- AND PHOTOVOLTAIC CONVERSION DEVICES}

R. Wichner, A. Blum, E. Fischer-Colbrie and It. Chau

MS. date: January B, 1970 


\section{Contents}

Abstract. . . . . . . . . . . . . . . . . . . . . . I

Int roduct loh. . . . . . . . . . . ................ 1

Theorecteal Vodel . . . . . . . . . . . . . . . . . . . . , 2

Devlce Physteal Nodel. . . . . . . . . . . . . . . . . . 2

Surface layer . . . . . . . . . . . . . . . . . . . . . . 2

Deplat lon bayer . . . . . . . . . . . . . . . . . . . . 6

Subatrate. . . . . . . . . . . . . . . . . . . . 7

Charge-cargleg Tranapre . . . . . . . . . . . . . . . . . . . . . 7

Minoriey Corrters in strince layer. . . . . . . . . . . . . . . . 7

Generaclon of corriers. . . . . . . . . . . . . . . . . . 11

Interfaces becween sublayers. . . . . . . . . . . . . . . . . . 12

Boundary Condtelons - surface . . . . . . . . . . . . . . . Is

Boundary condictons - keplecion-bayer biffe. . . . . . . . . . . . . . is

ceneratlon-itracess fodels. . . . . . . . . . . . . . . . . . 18

Opeleal Genetacton. . . . . . . . . . . . . . . . . . . . 17

Generarlon by Beca sources. . . . . . . . . . . . . . . . . . . 18

Computat fonal procedure. . . . . . . . . . . . . . . . . . . . . I

Dika Inpic. . . . . . . . . . . . . . . . . . . . . . . . . . . . 21

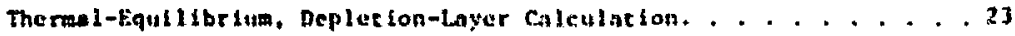

Shore-Cirenle Curreat, I sac . . . . . . . . . . . . . . . . . . 26

Forward Curtent Versass Voleage. . . . . . . . . . . . . . . . 33

Predlcted Performance . . . . . . . . . . . . . . . . . . . . . . 39

Expertmencal veriffeacton of todel. . . . . . . . . . . . . . . . . . 46

Discussion of Resules . . . . . . . . . . . . . . . . . . . . . 49

Conclustons. . . . . . . . . . . . . . . . . . . . . . . . . . 50

Acknowledgemenc . . . . . . . . . . . . . . . . . . . . . . . 51

References. . . . . . . . . . . . . . . . . . . . . . 51 


\title{
DESIGN OPTIMIZATION OF BETA- AND PHOTOVOLTAIC CONVERSION DEVICES
}

\begin{abstract}
This report prenente the theoretical and experimental resules of an 1.t.l. Electrenics Englneoring research program alocd at optinizing the design and electronle-anterlal parancers af beta- and photovoltaic p-n function cunversion devices. To meet this ofifective, a comprehensive couputer code has been developed that can handic a broad range of practical conditions.

The physteal wodel upon which the code $4 \mathrm{~s}$ based is described first. Then, an cxample Is given of $n$ sec of apeimization calculations along uleh the resulting optintzed efficienctes for 811 icon (Si) and gallium-arsentde (cass) devices. The model wo have developed, however, is not Ifalted to these waterlals. It can handle any appropriate materlal - single or polycrystalline - provided enerby-absorption and electron-transport data are avallable.

To check code validity, the performance of experimental silicon pan functinn dovices (produced in-house) were measured under vartous light Intensitien and spectra as well as under tritium beta irradiation. The results of cinese cents were then compared with predicted results based on the known or best estimiced device puranecers. The cosparison showed very goad agreement between the calculated and the measured results.
\end{abstract}

\section{Introduction}

The efflelency of beta- and photovoltalc conversion devices depend upon a large number of complex and Interrelated paraneters. An "Edisonian" approsch in obtaining aximun efficlency for epecific applications, therefore, is costly and the consting. Although such an expletical approach has yielded reasonably optimu efficiencies for $\$ 1$ photovoltalc cells used in space, design optial zation for terrestrial applications is not yet fully Baciafactory and optiaization for uses other than for the conversion of solar irradiation do not exist. The sicuption is even less desfrable when materials other than 5 i are considered. It is for this reason that we 
formulated a general use racher than highly specific computer model. Input parameters to this model include the optical spectrum of the incident light and its power level (or a characterization of the beta source), the energyabsorption properties of the materials under consideration, the physical cell dimensions, the doping leveis and profile gradients of the $p$ and $n$ regions (frot which carrier lifetimes, mobllities, and series resistance are calculaced In the prograw), and the effective shunt resistance of the cell.

Having proven the validity of the new beta-/photovoltaic computer code, we now have a valuable tool for producing optimized cells. Using this model, cell-development time can be reduced significantly. Moreover, the model makes it possible to calculate performance sensitivity for a single or a set of parameters, vital calculations for making intelligent compromises in both design and pruduction decisions.

\section{Theoretical Model}

DEVICE PHYSYCAL NODEL.

The device model analyzed by the code conolsts of a layer of one impurity type ( $p$ or $n$ ) on a substrate of opposite Impurity type (see Fig. 1). The device is assumed to be a homofunction (i.e., the same host material is used for the $p$ and the $n$ portions of the cell).

\section{Surface Layer}

The concentration of the dominant impurity type in the surface layer is assumed to vary with position, whereas the substrate is assumed to be uniformly doped. At a very early step, the logarithm of the actual impurity profile is replaced by a piecewise linear approximation. The device is partitioned into sublayers bounded by $Y_{1}, Y_{2}$, etc. (see FiB. 2). The logarithe of the iapurity concentration is assumed to vary linearly between the values $Y_{1}$ and $Y_{1+1}$. This Implies that the impurity concentration can be represented as

$$
N_{1} \exp \left(-\left(x-Y_{i}\right) / G_{1}\right)
$$




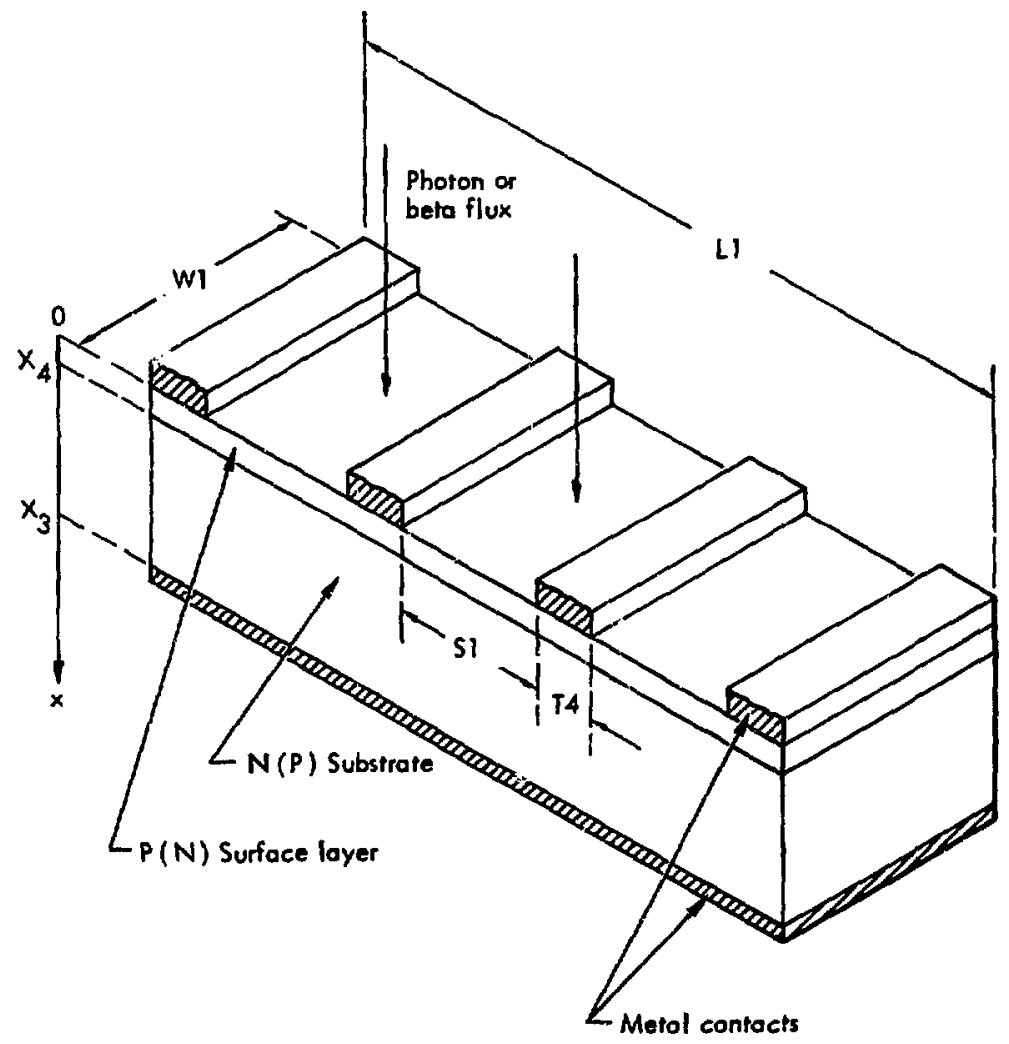

Fig. 1. Geometry of devices modeled. 


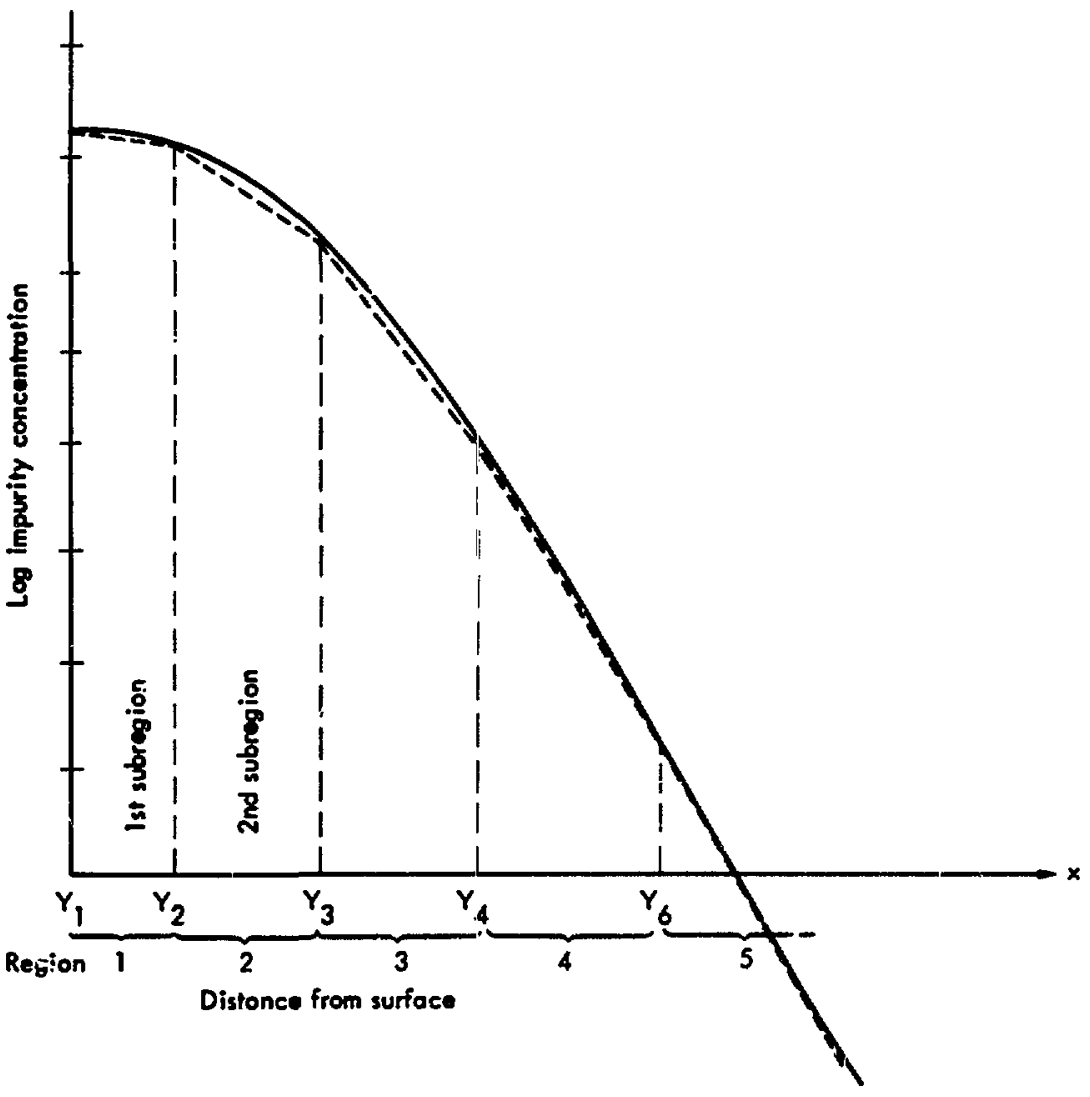

fig. 2. Piecewise liner representation of surface doping profile.

$-4-$ 
for $Y_{i}: x<Y_{i+1}$. This is referred to as the "exponential" approximation over the $i^{\text {th }}$ region. $N_{i}$ is the impurity concentration at $Y_{1}$.

In an undepleted region having such a nonconstant impurity concentration, there is an electric field. By assuming that the carrier concentration $N(x)$ is equal to the impurity concentration, one can derive the electric field at thermal equilibrium, this results in:

$$
E_{x}=-U \frac{k T}{q} \frac{1}{N} \frac{d N}{d x}
$$

where

$\mathrm{U}=+1$ for an $n-t y p e$ dopant,

$\mathrm{L}=-1$ ior a p-type dopant.

If the plecewise exponential approxination is used to compute the field, $E_{X}$, then over any one region, $Y_{1}<x \leq Y_{1}+1, E_{X}$ will be constant, $1 . e$..

$$
E_{x}=U \frac{k T}{q G_{1}} .
$$

The field will have a piecewise constant representation (see Fig. 3) up to the depletion layer. The minority carrier mobllity and iffetime will also vary with inpurity concentration. Their actual values are also approximated by piecewise constant values. The values are constant over the regions $Y_{1}<x<Y_{1+1}$. The values of these parameters are selected from published values in the literature. Whereas experigental verification of the selected values would be desirable because of their dependence on the device fabrication istory, the level of effort and cost involved in such measurcinears cends to prevent verification.

At each position $x$ within the cell, the minority carrier transport is characterized by an analytic solution of the transport equation over the sublayer containing $x\left(Y_{1}<x \leq Y_{1+1}\right)$ subject to the assumptions summarized below:

Constant field, E(1)

Constant minority carrier mobility, $u(t)$

Constant minority carrier lifetime, $T(i)$.

An appropriate set of constants is assigned to each region $Y_{i}<x \leq Y_{i+1}$. 


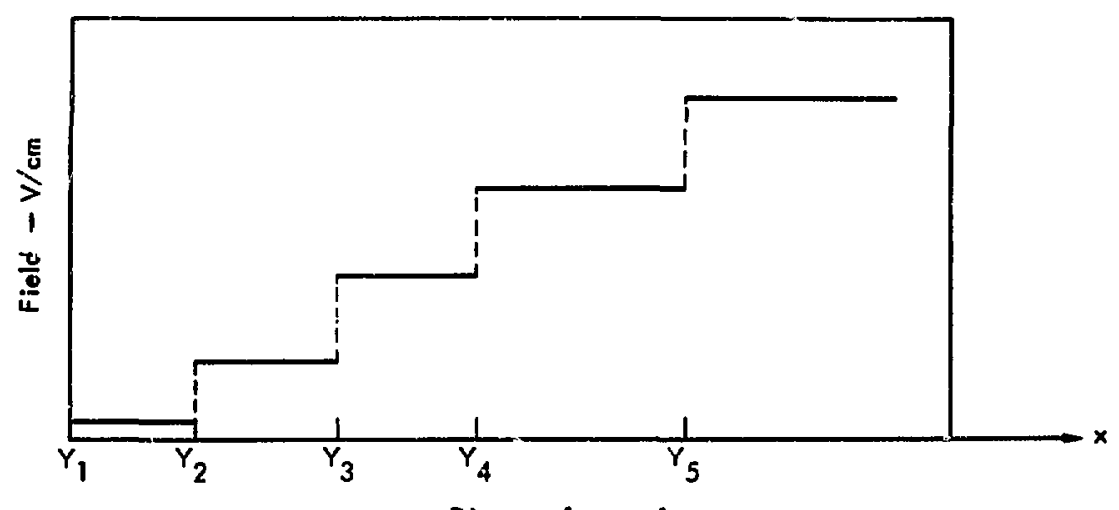

Distance from surface

Fig. 3. Piecewise constant fle'd in surface layer.

\section{Depletion Layer}

The depletion layer is assumed to be cotally depleted and the surrounding surface ar.] substrate regions are assumed to be quasi-neutral (charge neutra1, but supporting a field due to variations in impurity concentration). Net current density is assumed to be low enough that Boltzman boundary conditions for minority-carrier concentrations apply. It is further assumed chat majoricycarrier consentrations at junction edges are equal tu the impurity concentrations (1.e., low-level injection). Moreover, it is assumed that $X_{1}$ - the depletion layer edge - lies between $Y_{j}$ and $Y_{j-1}$, where $Y_{j}$ is the largest $Y_{i}$ value. $Y_{j}$ need not coincide with $x_{4}$, the metallurgical junction but algorithms for assigning the $\mathrm{Y}_{i}$ values by machine generally make this assumption. This is the case illustrated in Fig. 4. The exponential aporoximation for the surface constituent of the doping is assumed to be the same exponential between $Y_{f-1}$ and the end of the cell at $x=x_{3}$. These assumptions simplify the computer coding ard result in an assumed doping profile, within the depletion layer, of the form

$$
\mathrm{N}_{2}\left(\exp \left(-\left(\mathrm{x}-\mathrm{x}_{4}\right) / G_{1}\right)-1\right)
$$

where $x_{4}$ is the location of the metallurgfcal function. The exponental $\because$ rm is derived from the piecewise exponential approximation to the surface-impurity concentration. The constant term $-\mathrm{N}_{2}$ is derived from the assumption of constant 
baskgrount (substrate) doping. The jetails of this proftle are essent lal to execuling the potential ralculations.

Current is assumed to be determined by the rate at which minority carriers wan diffuse and drift between the dipletion-layer edges and/or points of photon or beta generation and the various sinks (contacts and surfaces). In the model, the current is not limited by the rate of thertionic emission over the potent ial batrier presented by the function.

\section{Subsirate:}

In Fig. $4, x_{2}$ marks the edge of the depletion layer nearest the substrate. Valucs of $x$ between $x_{2}$ and $x_{3}$ ife within the substrace. The substrate mode: is particularly simple. The substrate is assumed to be uniform with respect to the assumed impurity concentration $x_{2}$, the minorit;-cartier diffusion constant $D_{2}$, and the lifet ime $\mathrm{T}_{2}$.

\section{CHARE.-CGRRIEK TKANSPORT}

\section{Minorily Carrfers in Sulface Layer}

is explainod proviously. the surface layer is divided into sublayers of uniform mobility, field, and lifetime. Analysis of carrier transport begins by computing tho transport across one of these sublayers and characterizing that trassport with a matrix.

If there are cexcess ininority carriers per $\mathrm{cm}^{3}$, particle current in the $+x$ direction is

$$
J_{x}=-D \frac{d C}{d x}+U_{u} E_{x} C
$$

where

$$
\begin{aligned}
u & =\text { mobility, } \\
D & =\frac{k T}{q} u=\text { diffusion constant, } \\
E_{x} & =\text { electrir field (in +x direction), }
\end{aligned}
$$

and, as before,

$$
\begin{aligned}
U & =+1 \text { for holes ( } \underline{n} \text { on } p \text { substrates) } \\
& =-1 \text { for electrons ( } \underline{p} \text { on } n \text { substrates). }
\end{aligned}
$$






Fig. 4. Assumed doping profile of devices modeled. 
The continuity equation, allowing for but assuming no recombination, is

$$
\frac{d J}{d x}+\frac{c}{\tau}=0,
$$

where, in this case, $\tau$ refers to minority-carrier lifetime. Inserting Eqs. (2) and (3),

$$
\frac{d^{2} C}{d x^{2}}-\frac{U g}{k T} \quad E_{x} \frac{d C}{d x}-\frac{C}{L^{2}}=0,
$$

where

$$
L^{2}=D T \text {. }
$$

The resulting equation is linear and thus, in principle, simple to solve, but the algebra is somewhat tedious. The solutions to Eq. (4) are:

$$
\begin{aligned}
C(x)= & A \exp \left(\frac{1}{2} U E_{x}^{\prime} x\right) \operatorname{Cosh}\left(\frac{x}{2} \sqrt{\left.E_{x}^{\prime 2}+4 / L^{2}\right)}\right. \\
& +B \exp \left(\frac{1}{2} U E_{x}^{\prime} x\right) \sinh \left(\frac{x}{2} \sqrt{\left.E_{x}^{\prime 2}+4 / L^{2}\right)},\right.
\end{aligned}
$$

where $A$ and $B$ are constants selected to satisfy the boundary conditions, $E_{x}^{\prime} \equiv E_{x} /(k T / q)$, and the origin is essentlally unspecified.

Now, assume that $\mathrm{C}$ and $\mathrm{dC} / \mathrm{dx}$ are known at some point $\mathrm{Y}$ and that we want to find $\mathrm{C}$ and $\mathrm{dC} / \mathrm{dx}$ at some point $\mathrm{Y}^{\prime}$. If both $\mathrm{Y}$ and $\mathrm{Y}^{\prime}$ lie within a common sublayer of the surface layer, one can use Eq. (5) with a shift of the coordinate origin to $\mathrm{Y}$,

$$
\begin{aligned}
C\left(Y^{\prime}\right)= & A \exp \left(\frac{1}{2} U E_{X}^{\prime}\left(Y^{\prime}-Y\right)\right) \cosh \left(\frac{Y^{\prime}-Y}{2} \sqrt{E^{\prime^{2}}+4 / L^{2}}\right) \\
& +B \exp \left(\frac{1}{2} U E_{X}^{\prime}\left(Y^{\prime}-Y\right)\right) \sinh \left(\frac{Y^{\prime}-Y}{2} \sqrt{\left.E^{\prime 2}+4 / L^{2}\right)},\right.
\end{aligned}
$$

which must also be a valid solution. By evaluating at $Y^{\prime}=Y$,

$$
A=C(Y)
$$

Taking the derivative with respect to $Y^{\prime}$ and evaluating a $Y^{\prime}=Y$, one Finds that 


$$
B=\frac{\frac{d C(Y)}{d x}-\frac{1}{2} C(Y) U E_{x}^{\prime}}{\frac{1}{2} \cdot{\sqrt{E_{x}^{\prime 2}+4 / L^{2}}}^{2}} .
$$

By using these formulae for $A$ and $B$ and rearranging the expresston for $C\left(Y^{\prime}\right)$, one can arrive at the matrix shown in Eqs. (6) and (7).

$$
\begin{aligned}
& \begin{array}{c}
C\left(Y^{\prime}\right)=\exp \left(\frac{1}{2} U E_{X}^{\prime} z\right)\left[\operatorname { C o s h } \left(\frac{z}{2} \sqrt{E_{X}^{\prime 2}+4 / L^{2}}-\frac{U E_{X}^{\prime}}{\sqrt{E_{X}^{\prime 2}+4 / L^{2}}}\right.\right. \\
\sinh \left(\frac{z}{2} \sqrt{\left.E_{X}^{\prime 2}+4 / L^{2}\right)}\right] \quad C(Y)
\end{array} \\
& +\exp \left(\frac{1}{2} U E_{x}^{\prime} z\right) \frac{2}{\sqrt{E_{x}^{\prime 2}+4 / L^{2}}} \sinh \left(\frac{z}{2} \sqrt{\left.E_{x}^{\prime 2}+4 / L^{2}\right)} \frac{d C(Y)}{d x}\right. \\
& \frac{d C\left(Y^{\prime}\right)}{d x}=\exp \left(\frac{1}{2} U E_{x}^{\prime} z\right) \frac{2 / L^{2}}{\sqrt{E_{x}^{\prime 2}+4 / L^{2}}} \sinh \left(\frac{z}{2} \sqrt{\left.E_{x}{ }^{2}+4 / L^{2}\right)} \quad C(Y)\right. \\
& +\exp \left(\frac{1}{2} U E_{x}^{\prime} z\right)\left[\frac{U E_{x}^{\prime}}{\sqrt{E_{x}^{\prime 2}+4 / L^{2}}} \sinh \left(\frac{z}{2} \sqrt{E_{x}^{\prime 2}+4 / L^{2}}\right)\right. \\
& +\operatorname{Cosh}\left(\frac{z}{2} \sqrt{\left.E_{x}^{\prime 2}+4 / L^{2}\right)}\right] \frac{d C(Y)}{d x},
\end{aligned}
$$

where $Z=Y^{\prime}-Y$. Equations (6) can be expressed in matrix form as

$$
\left|\begin{array}{l|}
c\left(Y^{\prime}\right) \\
\frac{d C\left(Y^{\prime}\right)}{d x}
\end{array}\right|=M_{i}\left(Y^{\prime}-Y\right)\left|\begin{array}{c}
C(Y) \\
\frac{d C(Y)}{d x}
\end{array}\right|
$$

where $M_{1}\left(Y^{\prime}-Y\right)$ is a $2 \times 2$ matrix. The $i$ subscript indicates that the $Y$ and $Y^{\prime}$ positions are within the $i^{\text {th }}$ sublayer. 
Generation of Carriers

The incident photon or beta flux generates electron-hele pairs at a rate that varies with depth into the cell. To characterize this process, the cell is further divided into thin layers, $x_{9}$ wide ( $x_{9}$ being a programmer adjusted constant). The generation rate per unit area within one of these layers is determined by exactly calculating the rate per unte volume at the layer's center $\left(x=x_{8}\right)$ and then inultiplying the result by layer width $\left(x_{9}\right)$. This is clearly an approximation, which is accurate only if $x_{9}$ is much less than the characteristic absorption length of the generating species. The further approximation is made that the generation within $x_{9}$ takes place totally within an incremental slice centered within $x_{g}$ at $x=x_{8}$ (Fig. 5 ). The actual generation profile within $x_{9}$ is replaced by an equivalent delta function. Since this process is repeated for a series of slices, the result is a series of delta functions at various $x$ values, which represent the generation process. This is illustrated in Fig. 6.



Fig. 5. Energy deposition in the device. 


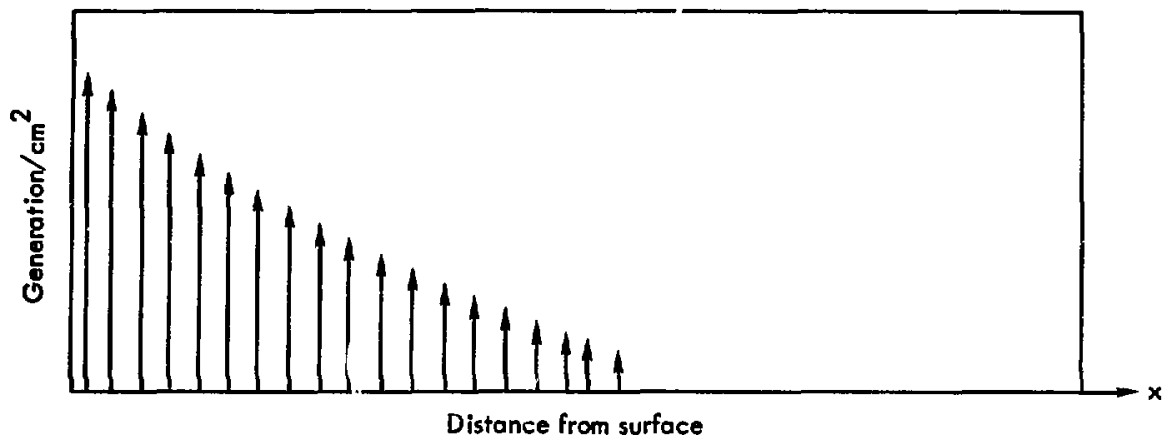

Fig. 6. Generation of charge carriers in the device.

Continuity of minority carriers imposes a boundary condition on the currents on either side of the delta function. While minority-carrier concentration must be continuous, abrupt changes in slope can occur. Furthermore, the electric field is assumed to be constant (within each sublayer). Continuity implies (see Fig. 7) that

$$
U \mathrm{UE}_{\mathrm{x}} \mathrm{C}(\mathrm{x})-\left.\mathrm{D} \frac{\mathrm{dC}(\mathrm{x})}{\mathrm{dx}}\right|_{x=\mathrm{x}_{8^{-}}}+\mathrm{GX}_{9}=\mathrm{UuE}_{\mathrm{x}} \mathrm{C}(\mathrm{x})-\left.\mathrm{D} \frac{\mathrm{dC}(\mathrm{x})}{\mathrm{dx}}\right|_{x=\mathrm{x}_{8}+},
$$

where $G$ is the generation rate per unit volume (at $x-x_{y}$ ). This reduces to

$$
\left.\frac{d C(x)}{d x}\right|_{x=x_{8}-}-\left.\frac{d C(x)}{d x}\right|_{x=X_{8}+}=\frac{G x_{g}}{D},
$$

where $D$ is a function of the particular sublayer within which the calculation is being executed.

\section{Interfaces Between Sublayers}

The approximation of allowing abrupt changes in $E_{X}$ field as we move from: one sublayer to the next requires abrupt changes in the computed carrierconcentration gradients, if continuity of minority-carrier concentration 


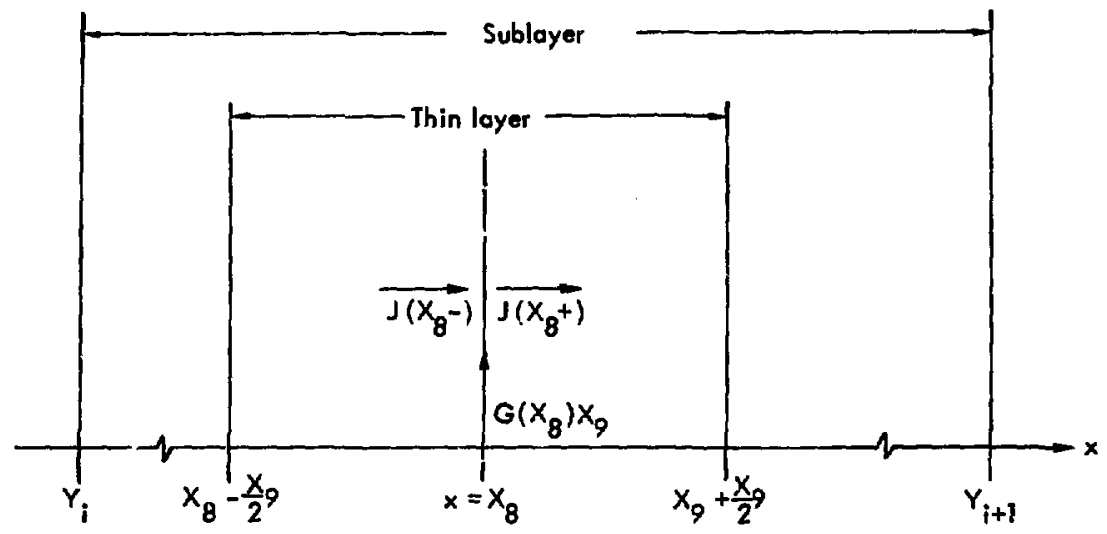

Fig. 7. Charge carrier generation and current flow in a sublayer of the device.

flow is to be malntalned.* Changes across a sublayer interface can be described by a simple $2 \times 2$ matrix. Particle-current denstry to the left of the interface at $Y_{1}$ (see Fig. 2) is given by

$$
U u_{1-1} E_{1-1} C_{1-1}\left(Y_{1}\right)-D_{1-1} \frac{d C_{1-1}\left(Y_{1}\right)}{d x} \text {. }
$$

Imacdiately to the right of $Y_{i}$, particle-current densicy is

$$
U U_{1} E_{1} C_{1}\left(Y_{1}\right)-D_{1} \frac{d C_{1}\left(Y_{1}\right)}{d x} \text {. }
$$

where the subscripts refer the sublayer in question. If the cartier conceneration is continuous.

$$
c_{1-1}\left(Y_{1}\right)=c_{1}\left(Y_{1}\right)
$$

* Alcernative:y, one could astume abrupt chsnges in the concentration, but such changex ace incutetvely lesa accepenble. 
Using this result and equating the two preceding currents,

$$
\begin{aligned}
U u_{1} E_{1} C_{1}\left(Y_{i}\right)-D_{1} \frac{d C_{i}\left(Y_{i}\right)}{d x}= & u u_{i-1} E_{1-1} C_{i}\left(Y_{i}\right) \\
& -D_{i-1} \frac{d C_{i-1}\left(Y_{i}\right)}{d x}
\end{aligned}
$$

or

$$
\begin{aligned}
\frac{d C_{1-1}\left(Y_{1}\right)}{d x}= & -v\left(\frac{u_{1} E_{1}-u_{1-1} E_{1-1}}{D_{1-1}}\right) C_{1}\left(Y_{1}\right) \\
& +\frac{D_{1}}{D_{1-1}} \frac{d C_{1}\left(Y_{1}\right)}{d x}
\end{aligned}
$$

Expressing these results in matrix form,

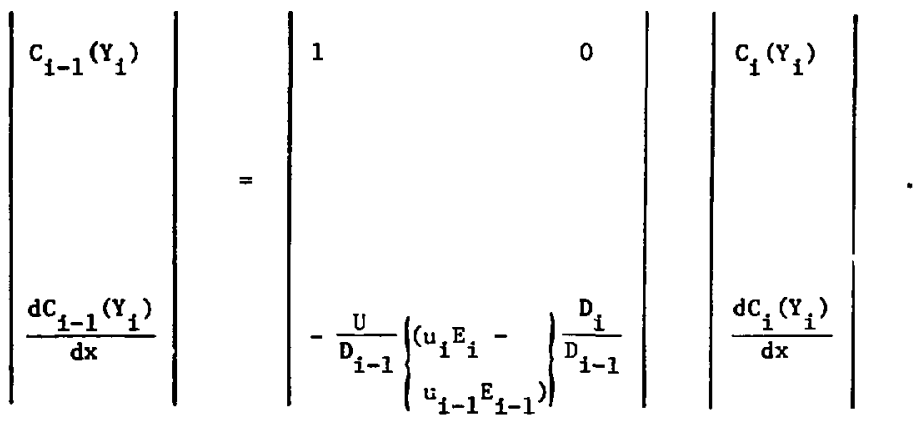

In more compact notation,

$$
V_{i-1}\left(Y_{i}\right)=N_{1-1, i} V_{i}\left(Y_{i}\right)
$$

The Inverse matrix $\mathrm{N}_{1,1-1}$ is

$$
\left|\begin{array}{cc}
1 & 0 \\
+\frac{U}{D_{i}}\left(u_{i} E_{i}-u_{i-1} E_{i-1}\right) & \frac{D_{i-1}}{D_{i}}
\end{array}\right| \equiv N_{i, i-1} .
$$

$-14-$ 


\section{Boundary Conditions - Surface}

The surface, positioned at $x=0$ in Fig. 1, is characterized by a recombination velocity $s$. Sublayer $\# 1$ is bounded by the surface $x=y_{1}=0$ and $x=Y_{2}$ (see Fig. 2). In this s iblayer, one has $E_{x}=E_{1}, u x u_{1}$, and $D=D_{1}$. The minority-carrier particle-current density is described by

$$
J=-D_{1} \frac{d C(x)}{d x}+U u_{1} E_{1} C(x)
$$

At the surface,

$$
-J=+D_{1} \frac{d C(0)}{d x}-U u_{1} E_{1} C(0)=C(0) s
$$

or

$$
\frac{d C(0)}{d x}=\left(\frac{S+U_{1} E_{1}}{D_{1}}\right) C(0) \equiv B_{8} C(0) .
$$

C(0) will depend upon the conditions of operation, whereas $B_{8}$ is a constant.

\section{Boundary Conditions - Depletion-Layer Edge}

At the interface of the quasi-neutral surface layer and the depletion layer, a boundary condition is established by assuming that a Boltzmann equilibrium has been established. In addition, low injection is assumed, implying that the majority-carrier concentration is approximately equal the net doping concentration. In the abrupt-junction case, the resulting boundary conditions are particularly simple; but in the case of graded-junctions, as considered here, additional analysts is required. Figure 8 shows the electrostatic-potential variation in the vicinity of the depletion layer under the conditions of: (1) thermal equilibrtum and (2) forward bias. Outside the depletion layer, the field is given by Eq. (1); inside the layer, it is detexmined by Poisson's equation. Surming potentials,

$$
\begin{aligned}
\Delta v_{n n}+\Delta v_{p p}+\psi_{0}+\Delta \psi & =\psi_{0}-v_{a p p}, \text { or } \\
-\Delta \psi & =\Delta v_{p p}+\Delta v_{n n}+v_{a p p},
\end{aligned}
$$




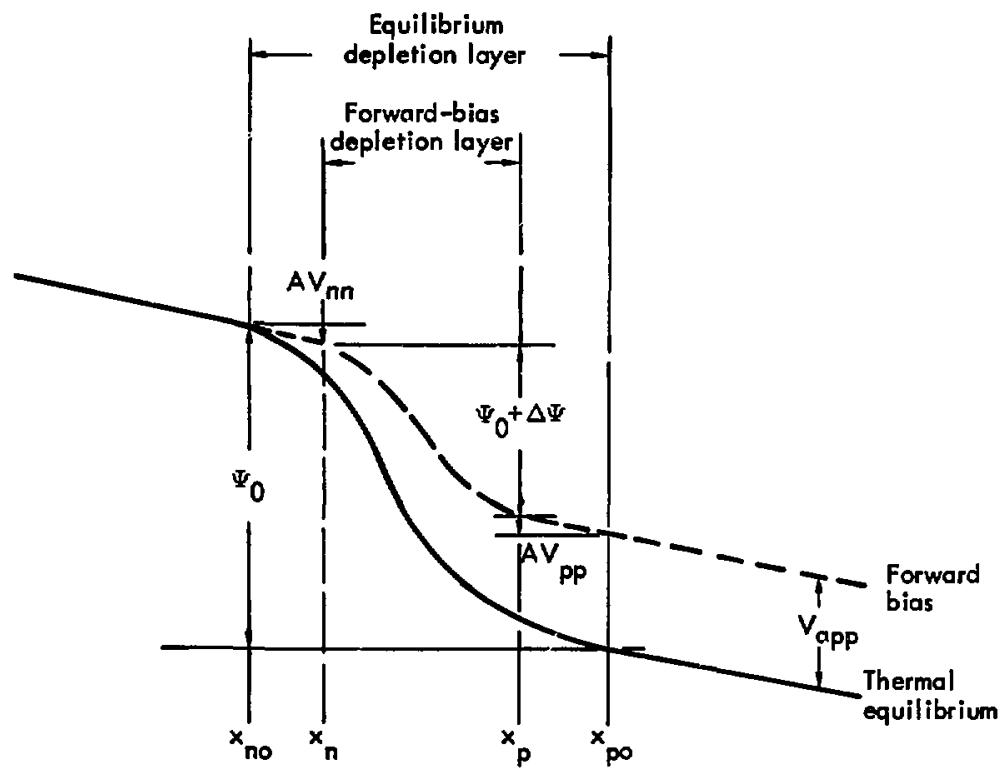

Fig. 8. Electrostatic-potential variation in vicinity of depletion layer at thermal equilibrium and under forward bias.

where

$\Delta V_{n n}$ and $\Delta V_{p p}$ are drops in the neutral regions (when quasi-neutral)

$\psi_{0}$ is the drop acrass the depletion layer at thermal equilibrium

$\Delta \psi$ is the increase in the drop across the depletion layer due co blas

$v_{\text {app }}$ is the externally applled forward blas.

A zero subscript Indicates the thermal equilibrium value. The Boltamann assumption yields

$$
\frac{n_{n}\left(x_{n}\right)}{N_{n}\left(x_{n o}\right)}=e^{-q \Delta v_{n n} / k T}
$$


and

$$
\begin{aligned}
& \left.\frac{n_{p}\left(x_{p}\right)}{n_{n}\left(x_{n}\right)}=e^{-q(\psi}+\Delta \psi\right) / k T \\
& =e^{-q\left(\psi_{0}-\Delta V_{n n}-\Delta V_{p p}-V_{a p p}\right) / k T} \\
& \left.n_{p}\left(x_{p}\right)=n_{n}\left(X_{n o}\right) e^{-q \psi_{o} / k T} e^{+q\left(\Delta V_{p p}\right.}+v_{a p p}\right) / k T \\
& =n_{p o}\left(x_{p o}\right) e^{q \Delta V} p p / R T e^{q V} a p p / R T \\
& n_{p}\left(x_{p}\right)=n_{p o}\left(x_{p}\right) e^{q V} a p p / R T=\frac{N_{i}^{2}}{p_{p o}\left(x_{p}\right)} e^{q V} a p p / k T .
\end{aligned}
$$

Similarly,

$$
P_{n}\left(X_{n}\right) \simeq \frac{N_{i}^{2}}{n_{n o}\left(X_{n o}\right)} e^{q V_{a p p} / k T} .
$$

\section{GENERATION-PROCESS MODELS}

\section{Optical Generation}

The energy spectrum of the optical source is tabulated at a discrete set of points by entering the power within the portion of the spectrum between points. The resulting spectra are in a format with 100 entries covering the range of wavelengths from $2.55 \times 10^{-7} \mathrm{~m}$ to $2.235 \times 10^{-6} \mathrm{~m}$. Thus, the entries are $210^{-8} \mathrm{~m}$ apart. Then, in a normalizing operation, the entries are divided by the total energy in the spectrum. The attenuation coefficient ( $\mathrm{n}$ units of $\mathrm{m}^{-1}$ ) is also tabulated at each point. The procedure Is to sum the rate of photon absorption with energies exceeding the bandgap at each value of $x_{8}$. The appropriate expression is

$$
G=\left(\sum_{j=1}^{j} A_{\max }^{\left(E_{s}\right)} A_{j}^{\prime} \exp \left(-A_{j}^{\prime} x_{8}\right) w_{j}\right) \frac{L_{o}}{h C_{o}} \tau_{7}
$$


where

$A_{j}^{\prime}$ is the attenuation coefficient

$Q_{j}^{\prime}$ is the normalized power in the $j^{\text {th }}$ slice of the spectrum

$W_{j}$ is the wavelength

$L_{0}$ is the total actual power in the optical spectrum

h is Planck's constant

$c_{0}$ is the speed of light

$T_{7}$ is the transmission coefficlent at the cell-air interface.

The term $\frac{\mathrm{w}_{j}}{\mathrm{hC}_{\mathrm{o}}}$ converts from energy to number of photons. $\mathrm{J}_{\max }$ is the subscript of the maximum wavelength with photon energies exceeding the bandgap. $\mathrm{J}_{\mathrm{min}}$ is determined by the intensity falloff of the source spectrum of short wavelengths.

Following each increment in $x_{8}$, the above sum is used to compute the generation rate at that value of $x$.

\section{Generation by Beta Sources}

The basic model stems from R. Loevinger's work, "The Dosimetry of Beta Sources in Tissue." 1 If $x$ is the actual distance between the source and the point at which absorption is being observed, one can define a dimenstonless varlable $r=\mu x$. Here, $\mu$ has the dimensions of an absorption coefficlent. The value of $\mu$ is given by an empirical fit to the absorption coeffictent

$$
\mu=16\left(2-\frac{E_{1}}{E_{7}}\right) E_{0}^{-1.40} \rho_{M} \mathrm{~cm}^{-1} \text {, }
$$

where

$E_{1}$ is the actual average energy per disintegration

E Is the hypothetical average energy per disintegration

$E_{0}$ is the maximum energy of the spectrum in Mev and

$\rho_{M}$ is the absorber mass density. 
Then, the tnergy absorbed per second per gram of material at a distance $x=r / \mu$ is

$$
I=\frac{k}{r^{2}}\{[c-r \exp (1-r / c)]+r \exp (1-r)\}
$$

ynere $k, c$, and $\mu$ are constants. The value of $c$ is given by

$$
c=3.11 \exp \left(-0.55 E_{0}\right) .
$$

The bracketed turm $[c-r \exp (1-r / c)]$ is assumed to be zero for $r \geq c$. The total rate of absorption in a medium of density $\mu_{m}$ is

$$
\int_{0}^{\infty} \rho_{m} 4 \pi x^{2} d x I(x)=\bar{E}=\text { energy output } / \mathrm{sec} .
$$

Evaluating the integral yields,

$$
k=-\frac{\mu^{3} \bar{E}}{\rho_{m} 4 \pi\left[3 c^{2}+\left(1-c^{2}\right) e\right]} \text {. }
$$

where $e$ is 2.71. Now, if one considers an integral of $f$ over a planar source $d x_{0}$ thick and assfgns the energy of one disintegration to $\bar{E}$, one finis

$$
d P=\int_{A_{S}} d x_{o} p_{a} R_{a} p_{m} d v I(r) d A_{s},
$$

wisere

$\mathrm{dA}_{\mathrm{s}}$ is an increment of the area of the planar source

$d x_{0}$ is the thickness of the planar source

$o_{\text {a }}$ is the density of radioactive atoms

$R_{a}$ is the disintegration race per radioactive atom

dy is the absorbing volume. 
If $x_{0}$ is the perpendicular distance between the planar source and the absorption point,

$$
\begin{aligned}
\mathrm{dP}= & \rho_{\mathrm{m}} \mathrm{dv} 2 \pi \rho_{\mathrm{a}} \mathrm{R}_{\mathrm{a}} \frac{1}{\mu^{2}} \\
& \cdot\left\{\left[\mathrm{kc} \ln \left(\frac{\mathrm{c}}{\mu \mathrm{x}_{\mathrm{o}}}\right)+\mathrm{kc}\left(1-\exp \left(1-\frac{\mu \mathrm{x}_{\mathrm{o}}}{\mathrm{c}}\right)\right]\right.\right. \\
& \left.+\mathrm{k} \operatorname{exf}\left(1-\ldots \mathrm{o}_{\mathrm{o}}\right)\right\} \mathrm{dx},
\end{aligned}
$$

where the bracketed term, [] , is zero for $\mu x_{0}>c$.

For a semi-infinite source, $d P$ must be integrated from $x$ to $\infty$, where $x$ is the distance from the point of abscrption to the beginning of the semiinfinite source. Then,

$$
\begin{aligned}
\frac{\text { power absorbed }}{\text { absorbing volume }}= & \rho_{\mathrm{m}} \frac{2 \pi \rho^{k} \mathrm{a}}{\mu^{3}} \\
& \cdot\left\{\left[-c^{2}\left(\frac{z}{c} \ell n^{z} \frac{z}{c}-\frac{z}{c}\right)+c z\right.\right. \\
& \left.+c^{2} \exp \left(1-\frac{z}{c}\right)\right]_{z=\mu x}^{z=c} \\
& \left.-\exp (1-x) \quad \begin{array}{l}
z=\infty \\
z=\mu x
\end{array}\right\},
\end{aligned}
$$

where the bracketed term, [] , is zero for $\mu x>c$.

Up to this point, the entire medium has been assumed to be homogeneous in density. Normally, however, the source density $\rho_{1}$ and the absorber density $\rho_{2}$ will be substantially different. One can lmagine compressing or expanding the source volume until its density is equal to that of the absorber. Such a process doss not alter the Incident radiation from a semiInfinite source. The affect of such an operation is to alter the density of radioactive atoms from $\rho_{a}$ to

$$
\rho_{a} \cdot \frac{\rho_{2}}{\rho_{1}} \text {. }
$$

As a final step, a reflection coefficlent is estimated for the incident beta particles at the source-absorber Interface and the total energy is divided by the energy deposited per hole-electron pafr. 


\section{COMPUTATIONAL PROCEDURE}

The theoretical model developed in the previous section has been programmed into a desk-top prop ammable calculator for sclution with the various input parameters. The computer code is divided into four main blocks:

- Block 1: Device description

- Block 2: Short-circuit calculation

- Bloc. s: Lutrenc-vollage calculation

- Block 4: Matrix subroutines.

The first three blocks are executed sequentially. The fourth block, containing matrix-manipulation subroutines, is accessed by blocks 2 and 3 . There is also a subroutine for computing the dimensions of and potential drop across the depletion layer. This subroutine, resident in block 3 , is accessed by block 2. A flow chart of the entire code program is shown in Fig. 9.

\section{Data Input}

A number of different input formats have been used. One of the more widely used optical-source models is described below. The calculator requests the following data to be entered:

70 Device thiciness, $X_{3}(\mathrm{~cm})$

$90 \mathrm{P} / \mathrm{N}$ or $\mathrm{N} / \mathrm{P} ; \mathrm{K} 9=1$ or 2 , respectively

170 Light intensity, LO (W/m²)

190 Maximum wavelength, wo (m)

210 Transmission coefficient, T7

The number of the statement at which data entry occurs, is indicated at the left. Via statements within the program, the following data are entered:

120 Number of subregions $+1, .15$

$\begin{array}{ll}\text { 240-260 Optical Parameters } & \text { W - wavelength (m) } \\ & Q \text { - Normalized spectral density } \\ & \text { A - Absorption coefficient, } M^{-1} \\ & -21-\end{array}$




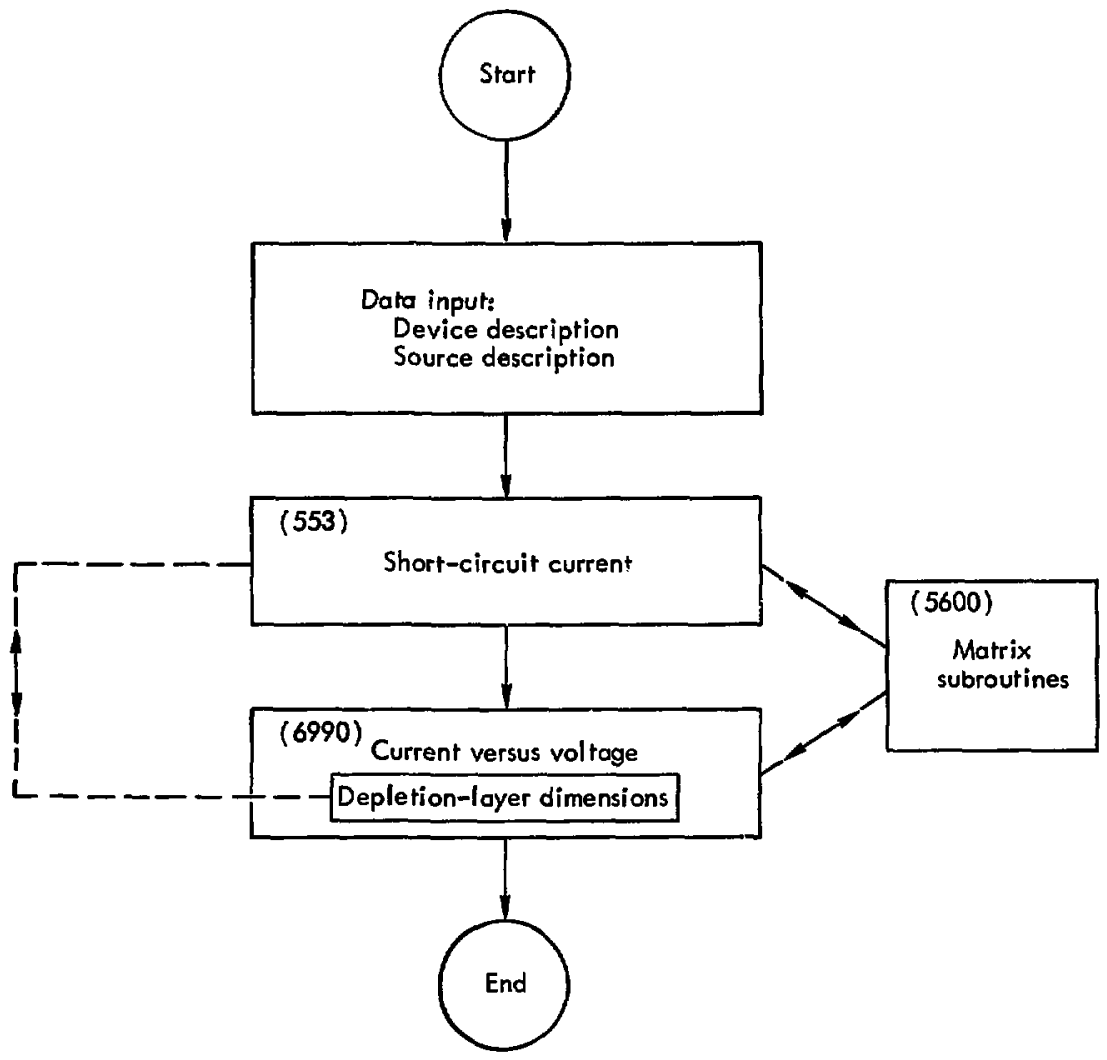

Fig. 9. Overall layout of photovoltaic computer code.

270 Cell length, LI (cm)

280 Cell width, WI (cm)

290 Material specific gravity, $\mathrm{RO}\left(\mathrm{gm} / \mathrm{cm}^{3}\right)$

400 Metallurglcal junction depth, $x_{4}(\mu \mathrm{m})$

460 Thin slice width, $x_{9}(\mathrm{~cm})$

470 Shockley Read recombination lifetime in the depletion layer $-\tau_{n}$, T3

480 Shockley Read recombination lifetime in the depletion layer $-\tau_{p}$ ' T8
(sec) 


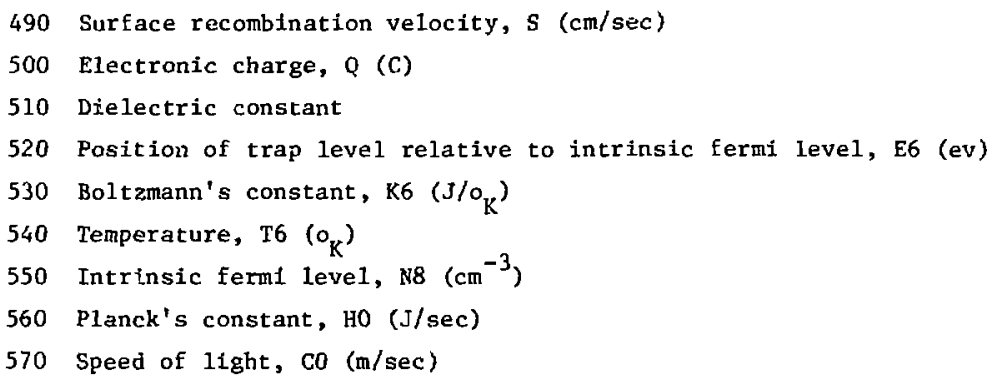

At this point, the program comes under a sequence of subroutine calls. Initialization of parameters and the input of additional data are the preliminary operations. This is illustrated in Fig. 10. Details of the fleld and exponential fittings were discussed in the surface layer section. The mobilities come from an empirical fit to Irvin's curves. 2 The lifetimes come from Fosson's empirical fitting ${ }^{3}$ of Kendall's data. ${ }^{4}$

Thermal-Equilibrium, Depletion-Layer Calculation

It is assumed during the short-circuit-current calculation that the potential drop and dimensions of the depletion layer correspond to those of the junction at thermal equilibrium. These parameters are determined by assuming some value of $\mathrm{x}_{2}$ as the starting point for computing the equilinrium state and by assuming some value of $\mathrm{x}_{1}$ as the starting point for the calculation.

The program now branches to the $\mathrm{x}_{1}$ calculation, for the given $\mathrm{x}_{2}$ value (see Fig. 11). When the subroutine has iterated to a satisfactory $\mathrm{X}_{1}$ estimate, a return is executed.

Now, knowing tentative values for $x_{1}$ and $x_{2}$, the potential drop across the depleted region is computed by integrating Poisson's equation. This result is compared with the Boltzmann condltion for the equilibrium potential difference corresponding to the electron concentration at $x_{1}$ divided by the electron concentration at $x_{2}$. If these two potentials do not compare closely, a new $\mathrm{x}_{2}$ value is selected and the cycle is repeated. But, if they do compare closely, a return is made to the main program. 


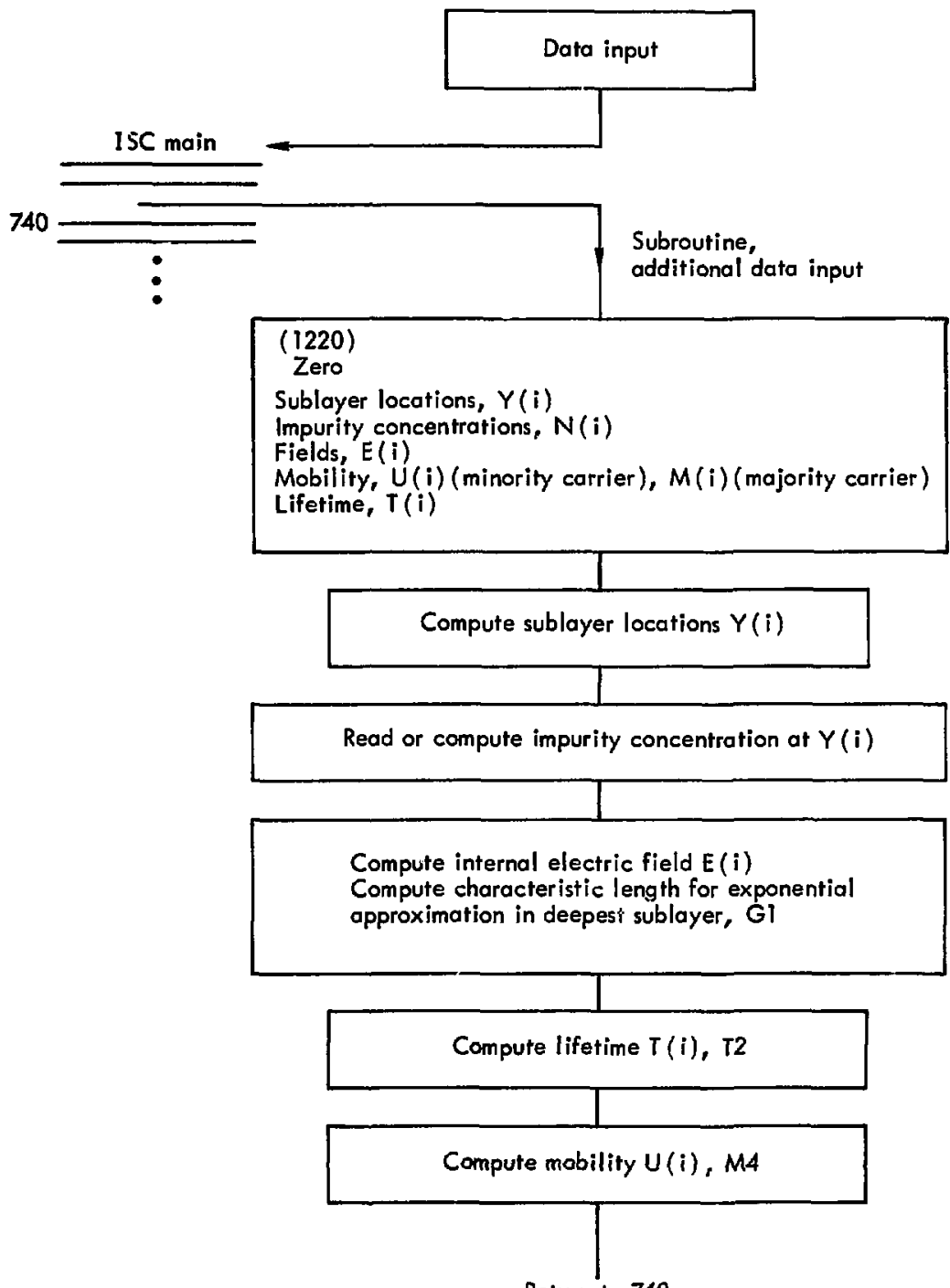

Return to 740

Fig. 10. Parameters and sequence of subroutines in photovoltaic code. 


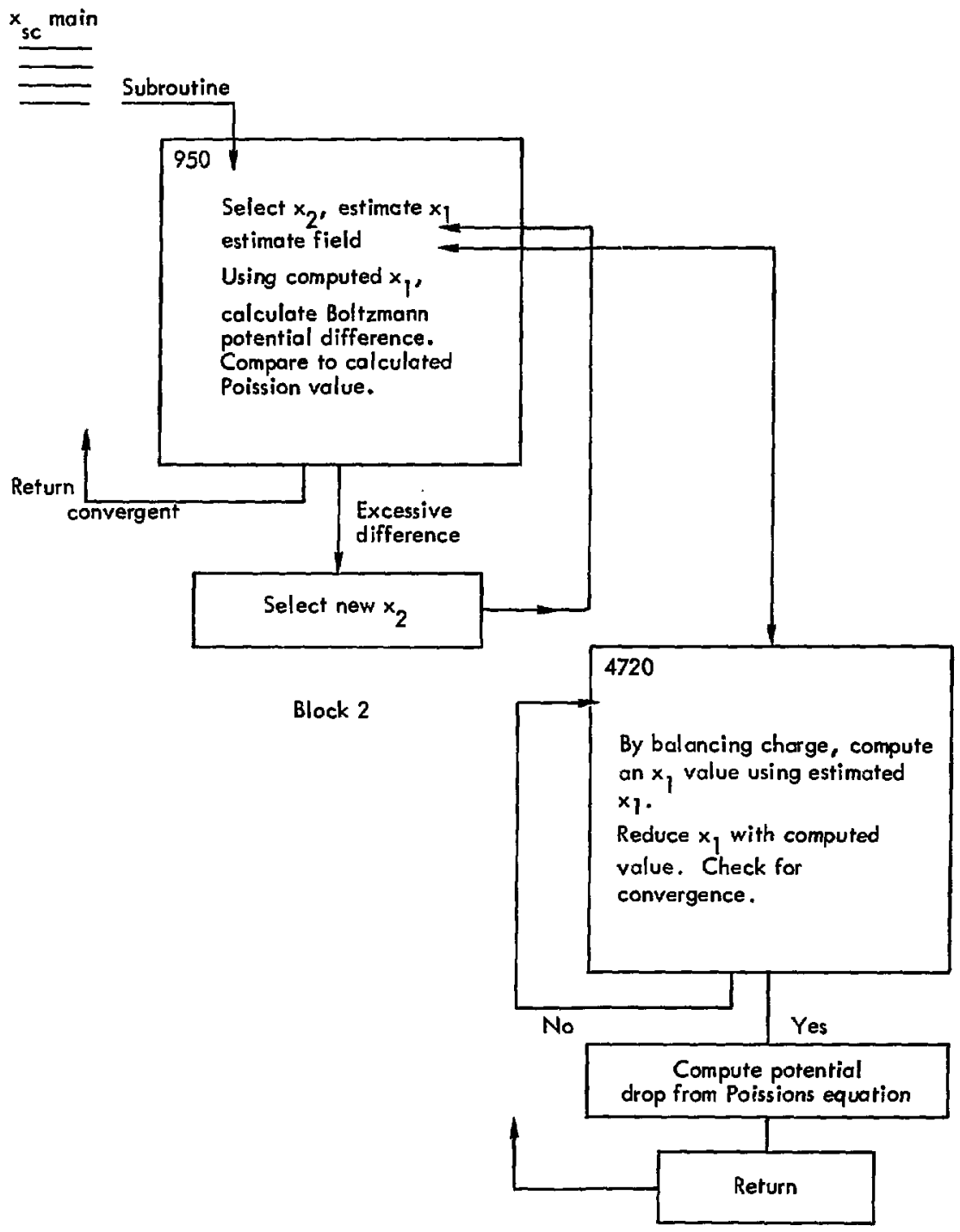

Block 3

FIg. 11. Subroutine for calculating incremental potentlal differences. 
When the thermal-equilibrium, depletion-layer ralculation is completed, the Initial operations are ended and the program enters the I sc current calculation.

Short-Circutt Current, I

The photon- or beta-generated short-circuit current is computed by using the matrices $M_{t}$ and $N_{1, i+1}$ discussed in the sections dealing with winority carriers in the surface layer and interfaces between sublayers. Parameters such as effective diffusion length and normalized field for each of the sublayers are computed first. Next the entries in the matrices are computed (Fig. 12). The program then enters a loop, as illustrated in Fig. 12. The point of observation $x_{8}$ is incremested. Generation within the thin silice $x_{8} \pm\left(x_{9} / 2\right)$ is computed by branching to a subroutine. The contribution of the generation to the short-circult current is computed in one of three program segwents, depending on the location of $x_{8}$. These alternative computations are discussed in the following subsections in terms of the matrices described previously.

Currents Induced by Generation in Surface Layer - As described earlfer, the surface layer is divided Into subregions, each characterized by a particular marrix $M_{1}\left(Y_{1}-Y_{1+1}\right)$, which connects the vector $\left(C_{1}\left(Y_{1}\right)\right.$, $\left.\frac{d C_{1}\left(Y_{1}\right)}{d x}\right)$ to the vector $\left(C_{1}\left(Y_{i+1}\right), \frac{d C_{1}\left(Y_{1+1}\right)}{d x}\right)$. The derivatives are the limiting values at the intertor edges of the th subregion. Simllarly, the matrix $N_{1-1,1}$ connects the vector $\left(C_{1}\left(Y_{1}\right), \frac{d C_{1}\left(Y_{1}\right)}{d x}\right)$, within the $i^{\text {th }}$ region, to the same vector on the other side of the boundary with the $1-1$ subregion. Within the limits of the approximations, these matrices, along with the boundary conditions, enable calculation of the short-circuit current. As shown In Fig. 13, the generation within the thin slice, $x_{9}$ wide centered at $x=x_{8}$, is approximated as a special impulse function at $x=x_{8}$. Minoritycarrier behavior is then characterized by the concentration at $x=x_{8}$ and the surrounding concentration gradients or, equivalently, by the vectora $v_{-}\left(x_{8}\right)$ and $v_{+}\left(x_{8}\right)$, (see section on interfaces between sublayers). 


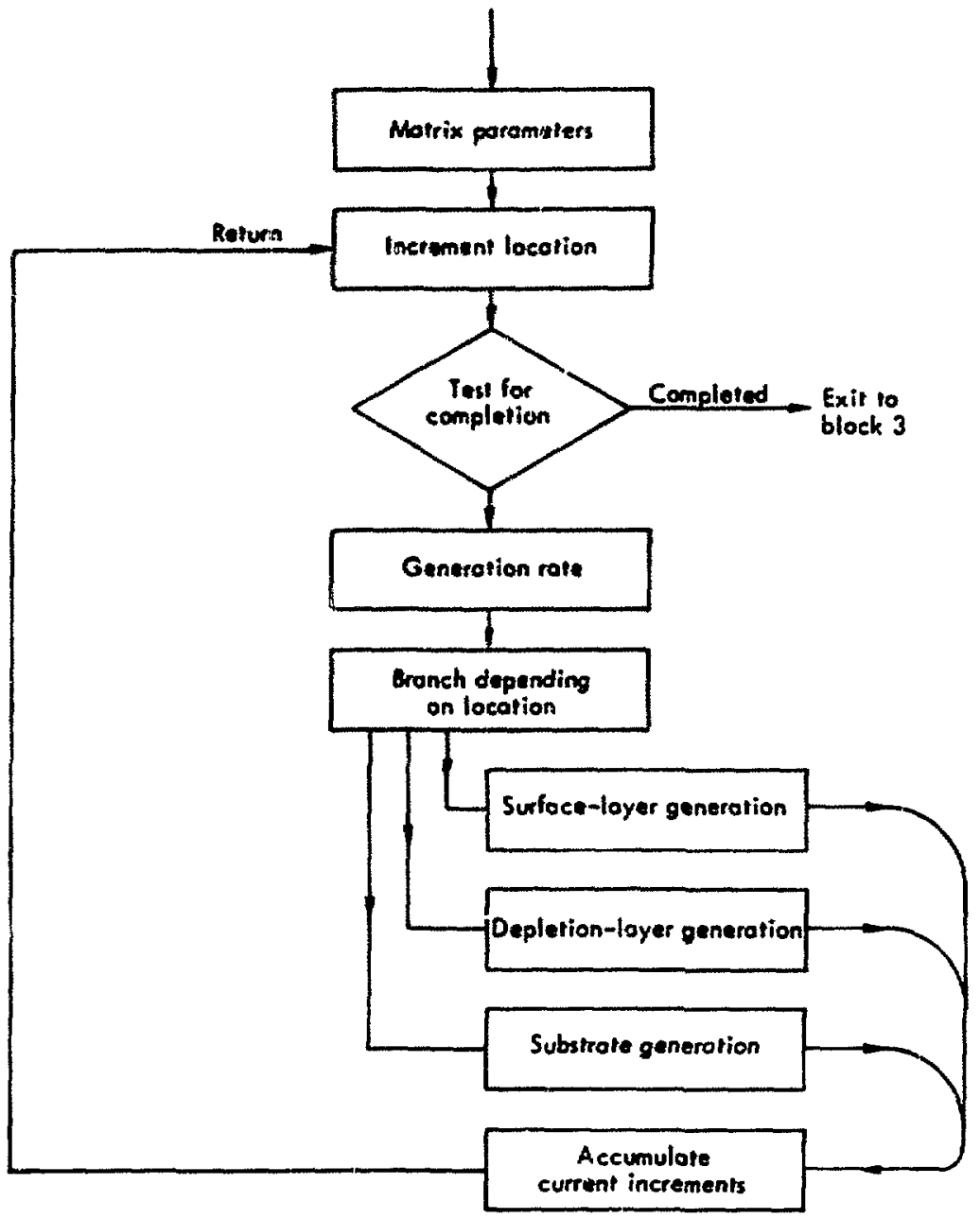

Fig. 12. Subroutine for calculating total carrier generation. 


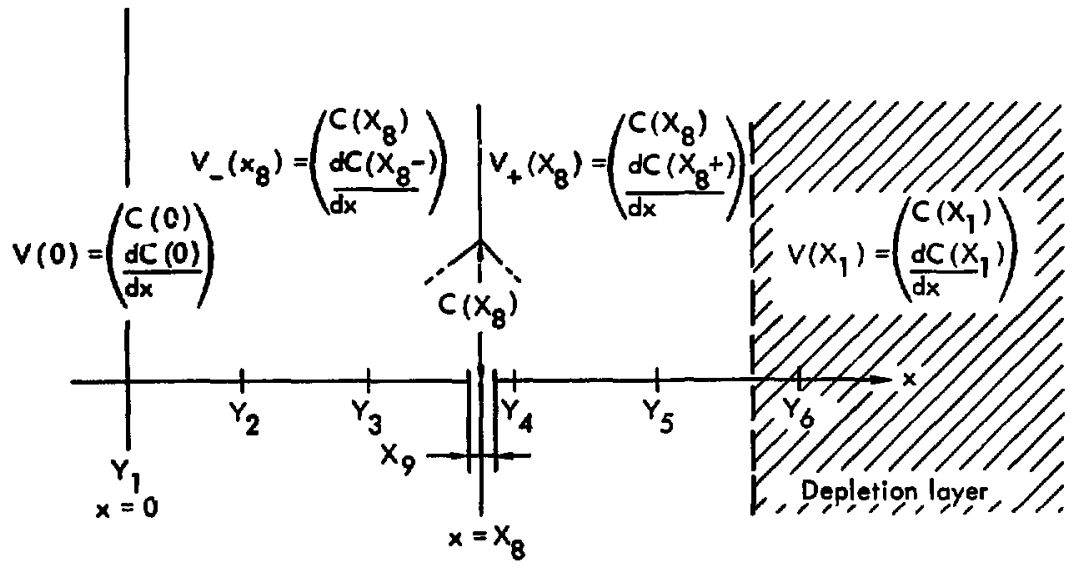

F18. 13. Model for Incremental potential.

As an illustration, assume that $Y_{3}<x_{8}<Y_{4}$. The vector $v_{-}\left(x_{8}\right)$ is related to $v(0)$ by

$$
\begin{aligned}
V_{-}\left(X_{8}\right) & =M_{3}\left(X_{8}-Y_{3}\right) \underbrace{N_{3,2} M_{2}\left(Y_{3}-Y_{2}\right) N_{2,1} M_{1}\left(Y_{2}-Y_{1}\right)}_{\bar{M}_{5}} V(0) \\
& =\underbrace{M_{3}\left(X_{8}-Y_{3}\right)}_{\bar{M}_{8}} \bar{M}_{5} V(0) \\
V_{-}\left(X_{8}\right) & =\bar{M}_{8} V(0)
\end{aligned}
$$


Here, $\overline{\mathrm{M}}_{5}$ and $\overline{\mathrm{M}}_{8}$ are defined explicitly to famlliarlze the reader with these symbols, which are used in the code.

$$
\begin{aligned}
& \text { Similarly, } V_{+}\left(X_{8}\right) \text { is related to } V\left(X_{1}\right) \text { by } \\
& \begin{array}{l}
V_{+}\left(X_{8}\right)=M_{3}\left(X_{8}-Y_{4}\right) \underbrace{N_{3,4} M_{4}\left(Y_{4}-Y_{5}\right) N_{4,5} M_{5}\left(Y_{5}-X_{1}\right)}_{\bar{M}_{4}} V\left(X_{1}\right) \\
V_{+}\left(X_{8}\right)=\underbrace{M_{3}\left(X_{8}-Y_{4}\right)}_{\bar{M}_{3}} \bar{M}_{4} V\left(x_{1}\right) \\
V_{+}\left(x_{8}\right)=\bar{M}_{3} V\left(x_{1}\right)
\end{array}
\end{aligned}
$$

Again, $\bar{M}_{3}$ and $\vec{M}_{4}$ are defined explicitly because of their use within the code. Equation (10a) can be simplified by using the boundary condition, Eq. (9), at the surface. First, Eq. (10a) is writcen as two equations:

$$
\begin{aligned}
& k_{8} C(0)+0_{8} \frac{d C(0)}{d x}=C\left(x_{8}\right) \\
& P_{8} C(0)+R_{8} \frac{d C(0)}{d x}=\frac{d C}{d x}\left(x_{8-}\right) .
\end{aligned}
$$

Then, from Eq. (9),

$$
\frac{\mathrm{dC}(0)}{\mathrm{dx}}=\mathrm{B}_{8} \mathrm{C}(0) \text {. }
$$

where $\mathrm{B}_{g}$ is a constant depending on $S, \mu_{1}, D_{1}$ and $E_{1}$. Hence,

$$
\left(\frac{\mathrm{k}_{8}}{\mathrm{~B}_{8}}+0_{8}\right) \frac{\mathrm{dc}(0)}{\mathrm{dx}}=\mathrm{c}\left(\mathrm{x}_{8}\right) \text {, }
$$

which can be rewritten as: $\quad k_{8}^{\prime} \frac{\mathrm{dC}(0)}{\mathrm{dx}} \equiv \mathrm{C}\left(\mathrm{x}_{8}\right)$.

Similarly,

which can be rewritten as:

$$
\begin{aligned}
\left(\frac{\mathrm{P}_{8}}{\overline{\mathrm{B}}_{8}}+\mathrm{R}_{8}\right) \frac{\mathrm{dC}(0)}{\mathrm{dx}} & =\frac{\mathrm{dC}\left(\mathrm{x}_{8-}\right)}{\mathrm{dx}}, \\
& \quad \mathrm{P}_{8}^{\prime} \frac{\mathrm{dC}(0)}{\mathrm{dx}}=\frac{\mathrm{dC}\left(\mathrm{x}_{8-}\right)}{\mathrm{dx}} .
\end{aligned}
$$


The currents are computed using a superposition argument. To compute the short-circult-ci-rrent component, zero excess carrier concentration is assumed at the depletion-layer edge. The location " the edge is approxinated ty assuming to to be the thermal equilibritum bias edge location. Under these conditions.

$$
C\left(x_{1}\right)=0
$$

and Eq. (10b) simplifies to

$$
\begin{aligned}
& 0_{3} \frac{d c\left(x_{1}\right)}{d x}=c\left(x_{8}\right) \\
& R_{3} \frac{d c\left(x_{1}\right)}{d x}=\frac{d c\left(x_{84}\right)}{d x} .
\end{aligned}
$$

Equation (8) is, in the notation of this section,

$$
\frac{d C\left(x_{8-}\right)}{d x}-\frac{d C\left(x_{8+}\right)}{d x}=\frac{G X_{9}}{E_{i}}
$$

where $D_{1}: s D_{3}$ because $x_{8}$ lies in subregion 3 (see Fig. 13) in this particular case.

Combining Eqs. (11) through (15),

$$
\begin{gathered}
\left(\mathrm{P}_{8}^{\prime} \frac{0_{3}}{\mathrm{k}_{3}^{\prime}}-\mathrm{R}_{3}\right) \frac{\mathrm{dC}\left(\mathrm{X}_{1}\right)}{\mathrm{dx}}=\frac{G X_{9}}{D_{1}} \\
\frac{\mathrm{dC}\left(\mathrm{K}_{1}\right)}{\mathrm{dx}}=\frac{G X_{9}}{D_{1}} \cdot \frac{1}{P_{8}^{\prime} \frac{0_{3}}{\mathrm{k}_{3}^{\prime}}-\mathrm{R}_{3}} .
\end{gathered}
$$

Since the excess concentration $C\left(x_{1}\right)$ is zero at the depletion layer edge, the flow at $x=x_{1}$ must be attributed to diffusion. Thus, the increment of flux at $x_{1}$ is

$$
\Delta F\left(x_{1}\right)=-D_{5} \frac{d C\left(x_{1}\right)}{d x}=-\frac{D_{5}}{D_{1}} \frac{G x_{9}}{P^{\prime} \frac{0_{3}}{k_{3}^{\prime}}-R_{3}},
$$


where $\mathrm{D}_{5}$ is the minority-carrier diffusion coustant at the edge of the depletion layer (region 5 in FIg. 13). The current. contribution from generat ion in the region surrounding $x_{8}$ is

$$
\Delta I=q \cdot \Delta F\left(\lambda_{1}\right) \cdot \operatorname{cell} \text { area. }
$$

Next, $x_{8}$ is incremented (by an amount $x_{9}$ ), the matrices are modified co correspond to the new lncation, and the above calculation is repeoted with the new matrix entrles. The sequence is repeated, with the current contributions accumulating, unt il $x_{8} \cdot x_{1}$.

Currents Induced by Generation in Deplecion Layer - The Incrementat irn of $x_{8}$ described in the previous section - is conctinued for values of $x_{1} \leq x_{8} \leq x_{2}$ (sec $f_{8}$. 4). As hefore, the generation rate at $x=x_{8}$ is computed, $G\left(x_{8}\right)$, and the generation within the slice,

$$
x_{8}-\frac{x_{9}}{2} \leq x<x_{8}+\frac{x_{9}}{2},
$$

per unit areas is given by

$$
G\left(x_{8}\right) X_{9}
$$

It is assumed that all the carriers generated within the depletion layer are swept to the adjacent neutral regions without recombination. Hence, the contribution to the short-circult current is

$$
\Delta I=q \cdot G\left(X_{8}\right) x_{9} \cdot \text { cell area. }
$$

The process is repeated with the current contributions accumulating until substrate neutral region is reached, $x-x_{2}$.

Currents Induced by Generation in the Substrate - The substrate is assumed to be uniform with respect to mobility, diffusion constant, and zero field. of the excess carriers generated within the substrate $x>x_{2}$, some wander onto the substrate contact $x=x_{3}$, where they recombine without contributing to the short-circuit current. Others recombine within the substrate, again without contributing to the short-circuit current $I$. The remaining excess carriers wander to the depletion-layer edge, experience a strong electric 
field, and are swept across to the surface layer. This component contributes to the short-circult current. Because of the simplictey of this region, the transport equations are solved awalyt leally, assuming zero blas, and the chort-clecuit-current contribution fis calculated from the resulting anilytic expressions.

The minortcy-zarrier cransport equation is

$$
-D_{2} \frac{d^{2} c}{d x^{2}}+\frac{C}{T_{2}}-0
$$

when $D_{2}$ and $T_{2}$ are the physical parameters in the substrate region. Subject to the boundary conditions

$$
\begin{array}{lll}
c=0 & \ominus & x=x_{2} \\
c=0 & x=x_{3}
\end{array}
$$

and assuming generation at $x=x_{8}$ oniy, the solutions are of the forms

$$
\begin{aligned}
& \sinh \left(\frac{x-x_{2}}{\sqrt{D_{2} T_{2}}}\right) \quad \text { for } \quad x_{2} \div x<x_{8}, \\
& -\sinh \left(\frac{x-x_{3}}{\sqrt{D_{2} T_{2}}}\right) \text { for } \quad x_{8}<x \leqslant x_{3} .
\end{aligned}
$$

The boundary condition at $x=x_{8}$ is

$$
D_{2}\left[\frac{d C\left(x_{8-}\right)}{d x}-\frac{d C\left(x_{8+}\right)}{d x}\right]=G\left(x_{8}\right) x_{9} \text {. }
$$

The flux of particles arriving at the depletion layer edge is

$$
D_{2} \frac{d C\left(x_{2}\right)}{d x} \text {. }
$$

Now, combining the solutions, boundary conditions, and particle-flux expression, the contribution to the short-circuit current is

$$
\Delta I=\frac{\sinh \left(\frac{x-x_{3}}{L_{2}}\right)}{\cosh \left(\frac{x-x_{2}}{L_{2}}\right) \sinh \left(\frac{x-x_{3}}{L_{2}}\right)-\sinh \left(\frac{x-x_{2}}{L_{2}}\right) \cosh \left(\frac{x-x_{3}}{L_{2}}\right)} q G\left(x_{8}\right) x_{9} A \text {, }
$$


where

$\mathrm{D}_{2}$ is the diffusion constant in the substrate,

T, is the lifecto in the substrate,

$1_{2}=\sqrt{i_{2} \mathrm{t}_{2}}$.

$G\left(x_{8}\right)$ is the generation rate per $c \pi^{3}$, and

A is the llluminated sreas.

\section{Forward Current Yersus voltiage}

$A$ sequence of forward blas voltages ( $V$ 's and VB's) is produced by decreasIng $x_{2}$ in increments and computing an $x_{1}$ and a forward-bias voltaga corresponding to each incremented $x_{2}$ value. For each resulting $x_{1}, x_{2}$, and v8 combination, the roncributions of injection into the surface layer, recombination is the depletion jayer, and injection into the substrate can be summed. The short-ircuit current is then subtracted from this sum, giving the net current. The manner in ihich the three components of the forward current are computed is described in the following subsections.

forward Current: Injection Into Surface Layer - The essential elements In calculating the injection of minority carriers into the surface layer and the resulting current were described in the sections describing the $M_{i}$ and $\mathrm{N}_{1}$ matrices and the boundary conditions at the surface and at $\mathrm{x}_{1}$.

The location of $x_{1}$ is computed for a given forward bias voltage. Then, the cascade of matrices is computed yielding the following equation:

$$
\begin{aligned}
& \left|\begin{array}{c}
c(0) \\
\frac{\mathrm{dC}(0)}{\mathrm{dx}}
\end{array}\right|=\underbrace{\frac{\mathrm{dC}\left(\mathrm{X}_{1}\right)}{\mathrm{dx}}}_{\frac{\mathrm{M}_{3}}{\mathrm{M}_{1}\left(\mathrm{Y}_{1}-\mathrm{Y}_{2}\right) \mathrm{N}_{1,2} \ldots N_{3,4} M_{4}\left(\mathrm{Y}_{4}-\mathrm{Y}_{5}\right) \mathrm{N}_{4,5} \overline{\mathrm{M}}_{5}\left(\mathrm{Y}_{5}-\mathrm{X}_{1}\right)}} \mid \\
& \left|\begin{array}{c|c}
c(0) \\
\frac{d C(0)}{d x}
\end{array}\right|=\bar{M}_{3}\left|\begin{array}{c}
c\left(x_{1}\right) \\
d C\left(x_{1}\right) \\
d x
\end{array}\right|=\left|\begin{array}{ll|l}
k_{3} & 0 & c\left(x_{1}\right) \\
P_{3} & R_{3} & \frac{d C\left(x_{1}\right)}{d x}
\end{array}\right| .
\end{aligned}
$$


As before,

$$
\frac{\mathrm{dC}(0)}{\mathrm{dx}}=\mathrm{B}_{B} \mathrm{C}(0)
$$

The resulting current at $x_{1}, I_{4}$, is

$$
I_{4}=q A\left(D_{5} \frac{d i\left(x_{1}\right)}{d x}-U \mu_{5} E_{5} c\left(x_{1}\right)\right) \text {. }
$$

With some algebraic manipulation,

$$
\begin{aligned}
I_{4}= & \frac{q A n_{1}^{2}}{N\left(x_{1}\right)}\left[\exp \left(q V_{a p p} / R T\right)-1\right] \\
& \cdot\left[D_{5}\left(\frac{P_{3}-B_{8} k_{3}}{B_{8} 0_{3}-R_{3}}\right)-U \mu_{5} E_{5}\right] .
\end{aligned}
$$

Hence, by knowing $x_{1}$, the matrix elements, and the applied junction voltage, one can calculate the injected current.

Forward Current: Recombination in Depletion Layer - When the diode structure is forward biased, holes from the p-side can recombine with electrons from the n-side as the two cross in the depletion layer. To estimate the contribution of this proress to the forwaid current, a single trap level, Sah-Noyce-Shockley model is used. Following the usual notation, the recombination rate is given by

$$
R=\frac{p n-n_{i}^{2}}{\left(n+n_{1}\right) \tau_{p e}+\left(p+p_{1}\right) \tau_{n o}} .
$$

By introducing quasi-fermi levels and the associated pseudo-Boltzmann statistics, one can express the above rate in terms of potentials:

$$
\begin{aligned}
& R=\frac{n_{i}}{\sqrt{{ }_{p o}^{T}{ }^{\tau} 0}} \frac{\sinh q \frac{\phi_{p}-\phi_{n}}{2 k T}}{\left[\cosh \left[\frac{q}{k T}\left(\psi_{i}-\frac{\phi_{p}+\phi_{n}}{2}\right)-\log \sqrt{\frac{\tau_{p o}}{\tau_{n o}}}\right]+\right.} \\
& \left.\exp \left(-q \frac{\phi_{n}-\phi_{p}}{2 k T}\right) \cosh \left(\frac{E_{t}-E_{i}}{k T}+\log \sqrt{\frac{\tau_{p o}}{T_{n o}}}\right)\right] \\
& -34-
\end{aligned}
$$


Using a negative coulomb scale, the varlous potencials ara plotted in Fig. 14. The usual assumption is made that $\phi_{p}$ and $\phi_{n}$ are constant with $x$. The result is that only one term in the preceding expression depends upon position $x:$ the $\cosh \left(\frac{\mathrm{q}}{\mathrm{kT}}\left(\psi_{\mathrm{c}}-\frac{\phi_{\mathrm{p}}+\phi_{\mathrm{n}}}{2}\right)-\log \sqrt{\frac{\zeta_{\mathrm{po}}}{\zeta_{\mathrm{no}}}}\right)$ term. The potential (negative coulomb) $\psi_{i}$ is approximated by a straight line $A^{\prime} x+B^{\prime}$. Then,

$$
R=\frac{C_{2}}{\operatorname{Cosh}\left[B A_{x}^{\prime}+B\right]+C_{1}},
$$

where $C_{2}$ and $C_{1}$ are independent of $x$.

The entries to this equation are

$$
\begin{aligned}
& c_{2}=\frac{n_{1}}{\sqrt{{ }_{\text {po }}{ }^{\top} \text { no }}} \sinh \left(q \frac{\phi_{n}-\phi_{p}}{2 k T}\right) \\
& B=\frac{q}{k T}
\end{aligned}
$$

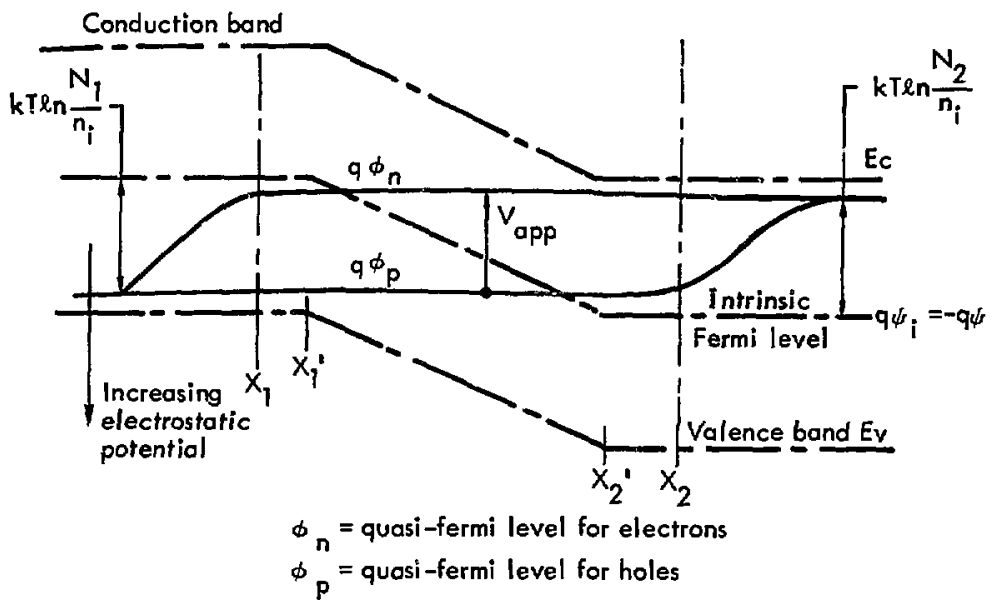

Fig. 14. Physical model of junction area. 


$$
\begin{aligned}
& c_{1}=\exp \left(-q \frac{\phi_{n}-\phi_{p}}{2 k T}\right) \cosh \left(\frac{E_{t}-E_{i}}{k T}+\log \sqrt{\frac{\tau_{p o}}{\tau_{n o}}}\right)>0 \\
& B=B^{\prime} B-\log \sqrt{\frac{\sqrt{\tau_{p o}}}{\tau_{\text {no }}}} .
\end{aligned}
$$

The forward current is an integral of this rate over the volume of the depletion layer

$$
I_{2}=q A c_{2} \int_{x_{1}^{\prime}}^{x_{2}^{\prime}} \frac{d x}{\cosh \left(B A_{x}^{\prime}+B\right)+C_{1}}+q A \int_{x_{1}}^{x_{1}^{\prime}} d x+q A \int_{x_{2}^{\prime}}^{x_{2}} d x \text {, }
$$

where $X_{1}^{\prime}$ and $X_{2}^{\prime}$ bound the region of linear potential. There are three different solutions to the first integral. The cholce depends on the value of $\mathrm{c}_{1}$. For $\mathrm{c}_{1}<1$,

$$
I_{2}=\frac{q A 2 C_{2}}{B A^{\prime} \sqrt{1-C_{1}^{2}}}\left[\tan ^{-1}\left(\frac{\exp \left(Y_{2}\right)+C_{1}}{\sqrt{1-C_{1}^{2}}}\right)-\tan ^{-1}\left(\frac{\exp \left(Y_{1}\right)+C_{1}}{\overline{1-C_{1}^{2}}}\right)\right] \text {, }
$$

where

$$
Y_{i}=B A^{\prime} x_{1}+B B^{\prime}-\log \sqrt{\frac{\tau_{p o}}{\tau_{n o}}}
$$

For $c_{1}=1$,

$$
I_{2}=\frac{q A 2 C_{2}}{B A^{\prime}}\left[\frac{1}{C_{1}+\exp \left(Y_{2}\right)}-\frac{1}{C_{1}+\exp \left(Y_{2}\right)}\right] ;
$$

and for $c_{1}>2$,

$$
\left.I_{2}=\frac{q A C_{2}}{B A^{\prime} \sqrt{C_{1}^{2}-1}} \ln \left(\frac{w-1}{w+1}\right)\right]_{W=}^{w=\frac{C_{1}+\exp \left(Y_{2}\right)}{\sqrt{C_{1}^{2}-1}}} \begin{gathered}
C_{1}+\exp \left(Y_{1}\right) \\
\sqrt{C_{1}^{2}-1}
\end{gathered},
$$

where

$$
Y_{1}=B A^{\prime} x_{1}^{\prime}+B B^{\prime}-\log \sqrt{\frac{\tau_{p o}}{\tau_{n o}}}
$$


The assumed potential variation ( $F / g$. 14) must be $f$ it to the actual variation to determine $A^{\prime}, B^{\prime}, X_{1}^{\prime}$, and $X_{2}^{\prime}$. Figure 15 illustrates the manner in which this fitring is performed, assuming an exponential doping $\left(N_{D}-N_{A}\right)$ frofile of the form

$$
U N_{2}\left(e^{-\left(x-x_{4}\right) / G} 4-1\right) .
$$
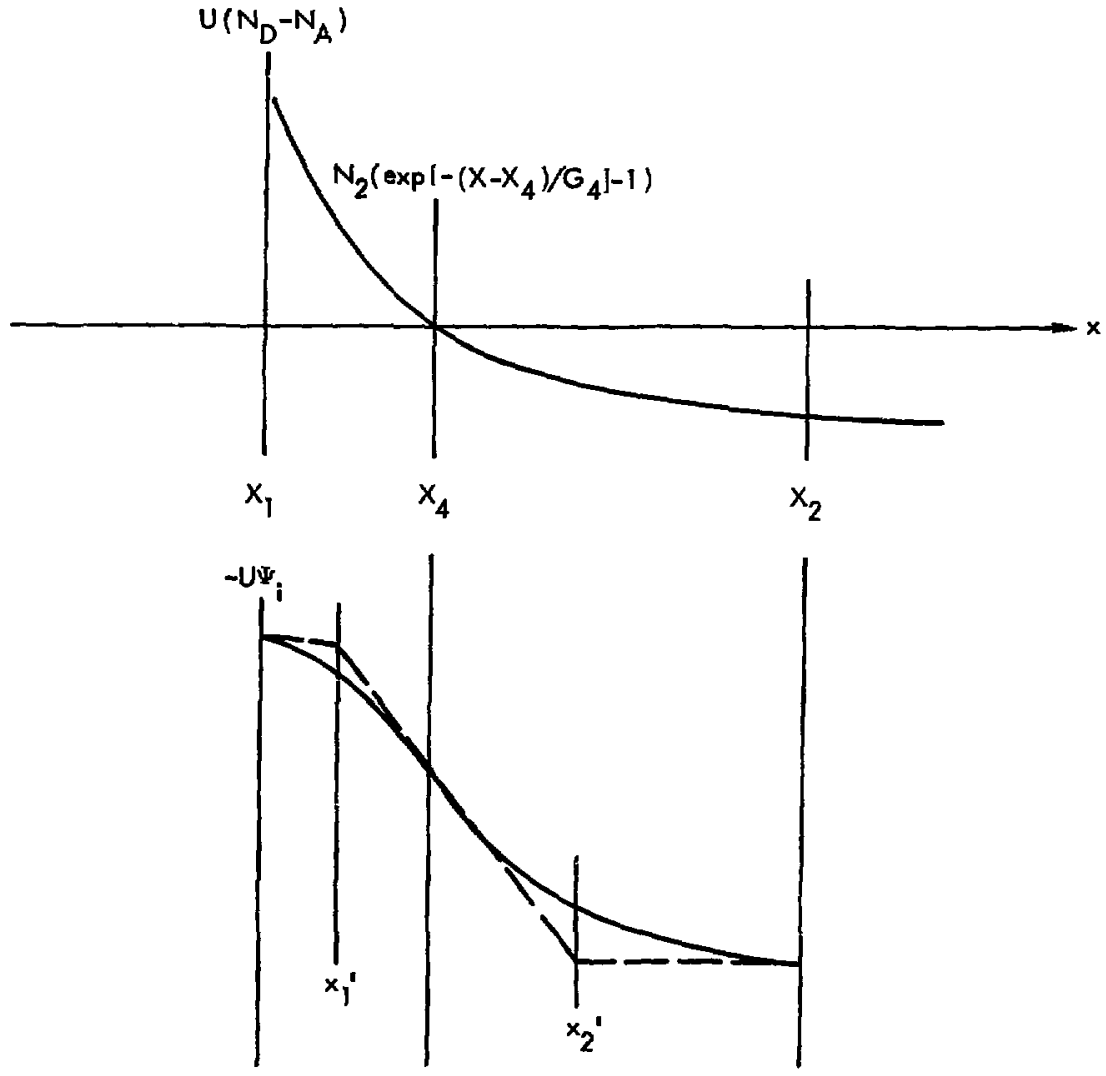

Fig. 15. Approximation for doping profiles. 
Note that $y_{4}$ is the location of the metallurglcal junction and that $G_{4}$ is a characterlstic length. The linear approximation is assumed to be asymptotic to the actual potential at $x-x_{4}$, from Gauss's Law; the actual field can be computed at $x_{4^{-}}$By an additional integration of $-U E(x)$ from $x_{1}$ to $x_{2}$, the potential drop from $x_{4}$ to $x_{2}-\Delta \psi_{2}-$ can be computed. Then,

$$
x_{2}-x_{4}=\left|\frac{\Delta \psi_{2}}{E\left(x_{4}\right)}\right|
$$

If $\mathrm{P}_{\mathrm{g}}$ is the total potential drop across the junction,

$$
x_{4}-x_{1}^{\prime}=\frac{P_{9}-\left|\Delta \psi_{2}\right|}{\left|E\left(x_{4}\right)\right|} .
$$

The recombination current in the regions $x_{1}<x<x_{1}^{\prime}$ and $x_{2}^{\prime}<x_{2}<x_{2}$ is relatively smail, but can be computed without much trouble once

$$
\psi_{i}-\frac{\phi_{p}+\phi_{n}}{2}
$$

is known. Examining Fig. 14, one can cee that, for $x_{1}<x<x_{1}^{\prime}$,

$$
\psi_{i}-\frac{\phi_{p}+\phi_{n}}{2}=\left[\frac{k T}{q} \ln \left(\frac{-U N\left(x_{1}\right)}{n_{1}}\right)-v_{a p p} / 2\right](-U) \text {, }
$$

where $N\left(x_{1}\right)$ is the net doping at $x_{1}$. Similarly, for $x_{2}^{\prime}<x<x_{2}$,

$$
\psi_{i}-\frac{\Phi_{p}+\Phi_{n}}{2}=\left[\frac{k T}{q} \ln \left(\frac{-U N\left(x_{2}\right)}{n}\right)-v_{a p p} / 2\right] U \text {, }
$$

where $N\left(x_{2}\right)$ is the net doping at $x=X_{2}$. When these values are inserted into Eq. (16) and the resulting rates are multiplied by the appropriate volume and charge,

$$
q A\left(x_{1}^{\prime}-x_{1}\right) \text { or } q A\left(x_{2}-x_{2}^{\prime}\right) \text {, }
$$

a value for the recombination currents in these regions' results. 
Forward Current: Injection into Substrate - The injection of carrfers into the substrate, under forward bias, is described by the transport equation

$$
-D_{2} \frac{d^{2} c}{d x^{2}}+\frac{C}{T_{2}}=0
$$

and two boundary conditions

$$
c\left(x_{3}\right)=0,
$$

and

$$
c\left(x_{2}\right)=\frac{n_{1}^{2}}{N\left(x_{2}\right)} \quad\left(e^{q V_{a p p} / k T}-1\right)
$$

The solution is

$$
C(x)=\frac{n_{i}^{2}}{\left|N\left(x_{2}\right)\right|}\left(e^{q} v_{a p p} / k T-1\right) \frac{\sinh \frac{x-x_{3}}{\sqrt{D_{2} T_{2}}}}{\sinh \frac{x_{2}-x_{3}}{\sqrt{D_{2} T_{2}}}}
$$

The associated current $I_{I}$ is calculated as follows:

$$
I_{1}=-\frac{q A D_{2} N_{1}^{2}}{\mid N\left(x_{2}\right) / \sqrt{D_{2} T_{2}}}\left(e^{q v_{a p p} / k T}-1\right) \cosh \left(\frac{x_{2}-x_{3}}{\sqrt{D_{2} T_{2}}}\right)
$$

\section{Predicted Performance}

The computer code for beta- and photovoltaic $p-n$ junctions has been used to optimize cell-design parameters. In these design-optimization studies, various realistic physical descriptions and electronic-naterial data were used to arrive at a set of plots for the efficiency versus junction depth, with material properties as parameters. The data obtained for the highest efficiency can be used as guidelines for final cell designs. 
Optimization data have been computed for the following radiation sources:

- Solar radiation under 1 atm, at $1000 \mathrm{~W} / \mathrm{m}^{2}$ power

- Laser 11 gnt of $1.06-\mu m$ wavelength at $100 \mathrm{w} / \mathrm{m}^{2}$ power

- Fluorescent light with a "cool white" spectrum at $2 \mathrm{~W} / \mathrm{m}^{2}$ power

- Tritium betas, "infinitely thick" source at 1400-torr pressure.

Table 1 shows the $S i$ and GaAs semiconductor properties and cell geometries used in computing the optimized design features.

The data and plots that were generated were then used to plot efficiency versus junction-depth curves as a function of several parameters. Figure 16 , an example of this approach, shows efficiency versus function depth of a GaAs cell 1lluminated by a $2-W / m^{2}$ cool-white fluorescent 1ight. The curves clearly demonstrate the effect of varying minority-carrier lifetime in the function and of surface dopant conentration. If desired, these calculations can be extended by using small increments in varying parameters.

The data shown here do not indicate the junction depth at which maximum efficiency is obtained. From stmilar computations, however, it can be shown that maximum efficiency lies between $0.03-$ and $0.1-1 \mathrm{~m}$ junction depth.

Table 1. Semiconductor and cell characteristics used in design-optimization studies.

$\begin{array}{lll}\text { Device thickness (cm) } & 0.018 & 0.018 \\ \text { Surface recombination veloctly (cm/sec) } & 10^{4}-10^{3} & 10^{4} \\ \begin{array}{l}\text { Mfnority-carrier lifetime in } \\ \text { depletion region (sec): }\end{array} & \\ \quad \tau_{\mathrm{e}} & 10^{-6}-10^{-9} & 10^{-7}-10^{-9} \\ \tau_{\mathrm{h}} & 10^{-7}-10^{-9} & 10^{-7}-10^{-9} \\ \text { Carrier concentration: } & 10^{17}-10^{20} / \mathrm{cc} & 10^{17}-3 \times 10^{18} \\ \mathrm{~N}_{1} \text { above junction (at surface) } & 10^{15}-10^{19} & 3 \times 10^{16}-10^{18} \\ \mathrm{~N}_{2} \text { below junction (in bulk) } & \end{array}$




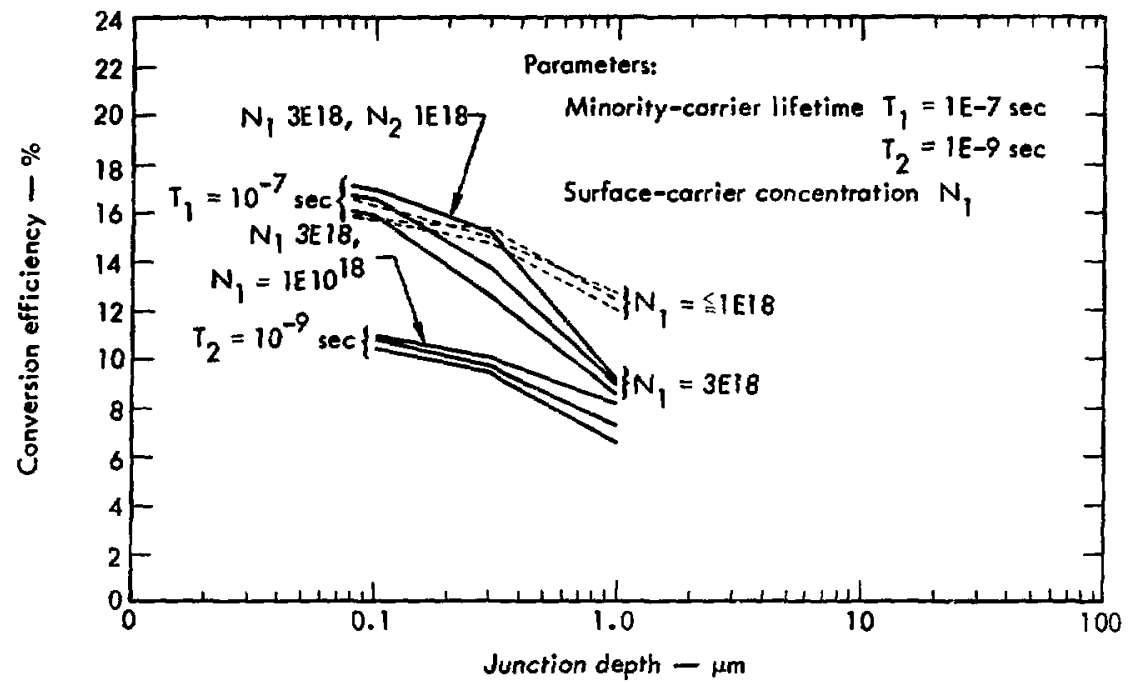

Fig. 16. Code-calculated conversion efficiency versus junction depth for p-on-n GaAs cell illuminated with $2 \mathrm{~W} / \mathrm{m}^{2}$ of cool-white fluorescent light.

It should be noted that at junction depths much less than $0.05 \mathrm{hm}$, the accuracy of the calculations decrease. No calculations were made for junction depths less than $0.03 \mathrm{\mu m}$ because uncertainty in the results could have clouded our conclusions. The trend of this curve towards smaller junction depths is determined by the series resistance (which can be somewhat controlled by optimizing the electrode grid structure), and the trend towards larger junction depths is detarmined by the optical absorption properties of the material.

The plots in Fig. 16 demonstrate the compromises in efficiency to be expected, if for technical or economic reasons, a certain junction depth is required. The figure also shows that, for GaAs, the sensitivity of the efficfency as a function of junction depth is less for surface concentrations equal to or less than $10^{18} / \mathrm{cm}^{3}$ than for surface concentrations of $3 \times 10^{18} / \mathrm{cm}^{3}$ or larger. Although this effect can generally be expected from the rapid decrease in mobility of GaAs at these dopant concentrations, the code provides actual numerical values for the change. 
A sample printout of the computer code is shown in Table 2. In addition to efficiency information, the code provides data on open-circuit voltage, short-circult current, series resistance, maximum power, voltage and current at the maximum power point, and a fill factor for the given spectrum, level of illumination, and material and geometrical cell-design parameters. The I-V curves can be plotted automatically for each set of design parameters.

Design features of $S 1$ and GaAs cells have been optimized in detail, using the code. In addition, pertinent data are available for a number of other materials Including $\mathrm{Ge}$ and $\mathrm{CdTe}$, so that equivalent optimization data can be determined for them.

Figures 17 through 20 show optimized efficiency versus junction depth for:

- $100 \mathrm{~mW} / \mathrm{cm}^{2}$ simulated solar radiation

- $0.2 \mathrm{~mW} / \mathrm{cm}^{2}$ fluorescent 1 ight

- $10 \mathrm{~mW} / \mathrm{cm}^{2} 1.06-\mu \mathrm{m}$ laser "light"

- $\quad 32 \mu \mathrm{W} / \mathrm{cm}^{2}$ tritium beta radiation.

Figure 17 shows optimized data for a silicon photovoltaic cell operating under $100 \mathrm{~mW} / \mathrm{cm}^{2}$ (simulated) solar radiation. The data shows that an " $n$ on $p$ " structure should be used and, with the parameter increments chosen, one should use a $10^{16} / \mathrm{cm}^{3}$ p material as a substrate ( $1.4 \mathrm{ohm}-\mathrm{cm}$ ), given a substrate thickness of $0.45 \mathrm{~mm}$. The n-surface doping concentration should be $10^{20} / \mathrm{cm}^{3}$, and the junction depth should be $0.08 \mu \mathrm{m}$ (or less). Whether or not such a junction depth is practical for high-yield production is a question to be answered by a manufacturer. In the code, minority-carrier lifetimes in the junction were assumed to be $10^{-8}$ sec for both carriers.

Figure 18 shows computed data as optimized efficiency versus junction depth for Si and GaAs conversion devices under $2 \mathrm{~W} / \mathrm{m}^{2}$ cool-white fluorescent 1ight. The plot shows that GaAs is the best choice: n-on-p design, with an n-doping level of $3 \times 10^{18} / \mathrm{cm}^{3}$ and the p-substrate material having a dopant concentration of $10^{18} / \mathrm{cm}^{3}$. The plot also shows the effect of having minoritycarrier lifetimes of $\tau_{e}=\tau_{h}=10^{-7} \mathrm{sec}$ and $\tau_{e}=\tau_{h}=10^{-9}$ sec for GaAs, with the shorter lifetime cells having the smaller conversion efficiency (efficiency loss by a two-magnitude reduction of depletion-layer lifetime is about $30 \%$ ). Short lifetime GaAs devices perform comparably to the longer-lifetime si cells, wh reas $p-o n-n$ Si cells show only one third the efficiency computed for the best GaAs sell, probably because of the low hole mobility in Si. 
Table 2. Data printout for GaAs cell exposed to fluorescent light.

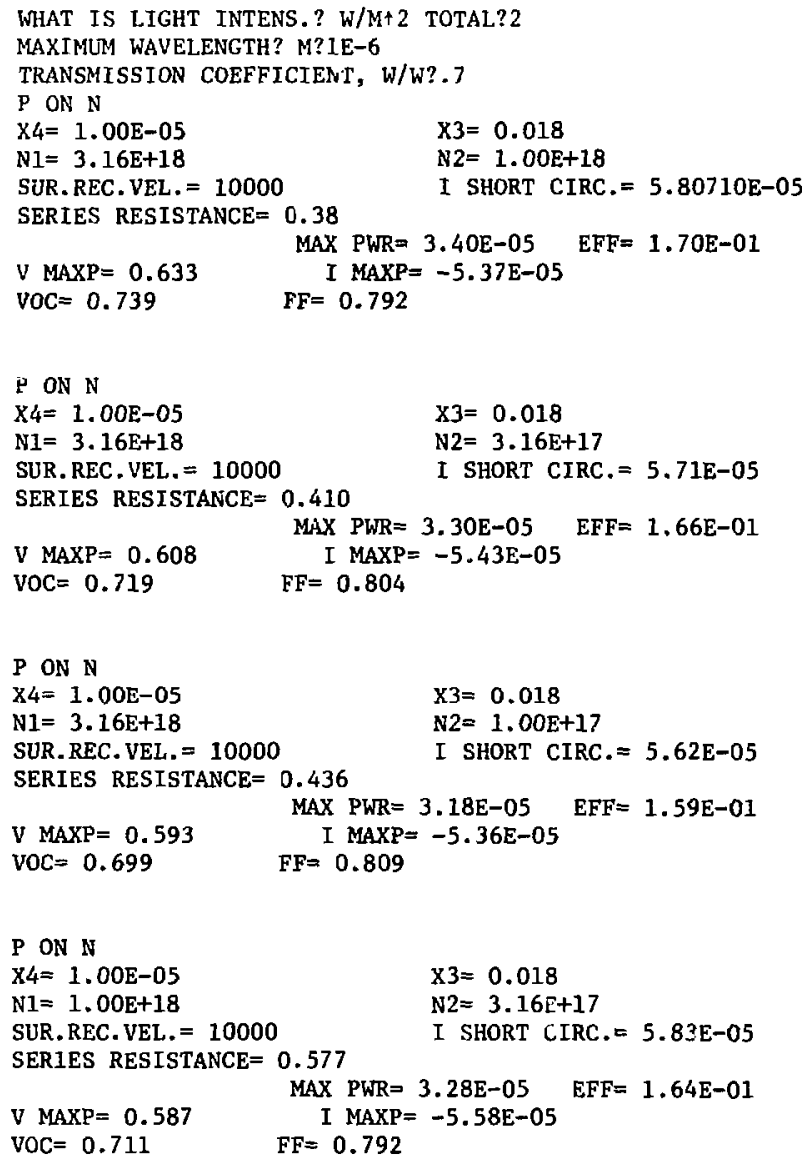
MAX PWR $=3.28 E-05 \quad E F F=1.64 E-01$




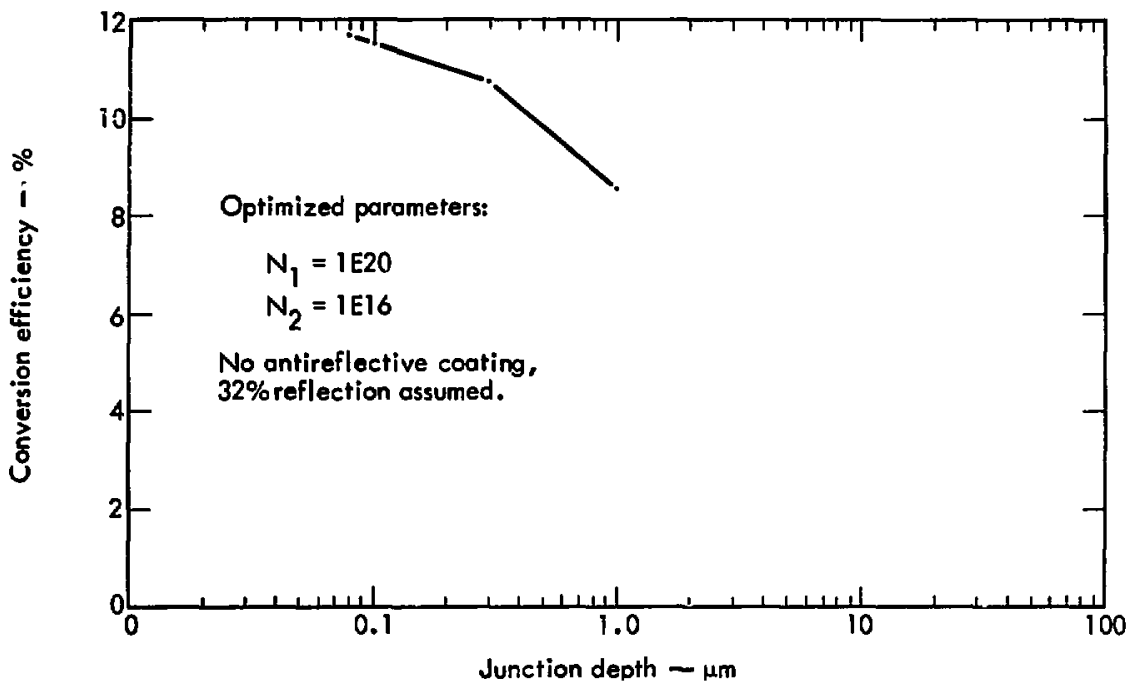

Fig. 17. Code-calculated conversion efficiency versus junction depth for n-on-p Si cell exposed to simulated solar radiation $\left(1000 \mathrm{~W} / \mathrm{m}^{2}\right)$.

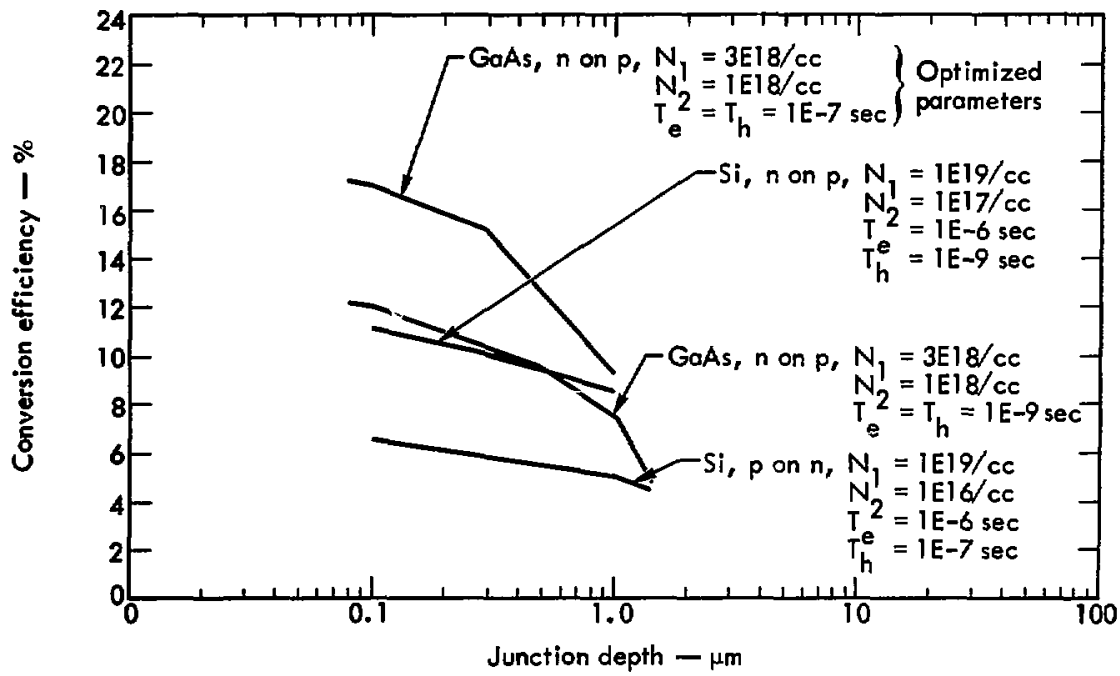

Fig. 18. Code-calculated conversion efficiency versus junction depth for GaAs and $\mathrm{Si}$ cells illuminated with $2 \mathrm{~W} / \mathrm{m}^{2}$ cool-white fluorescent light. 


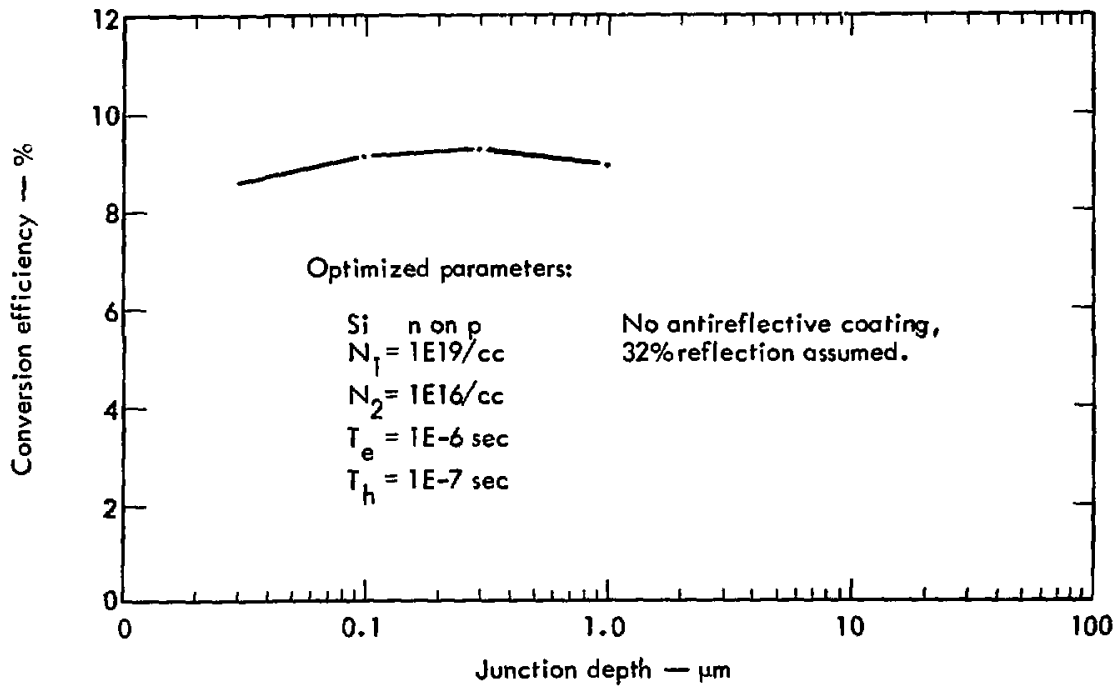

Fig. 19. Code-calculinted conversion efficiency versus junction depth (illumination: $1.06-\mu \mathrm{m}, 10-\mathrm{mW} / \mathrm{cm}^{2}$ laser 1 ight).

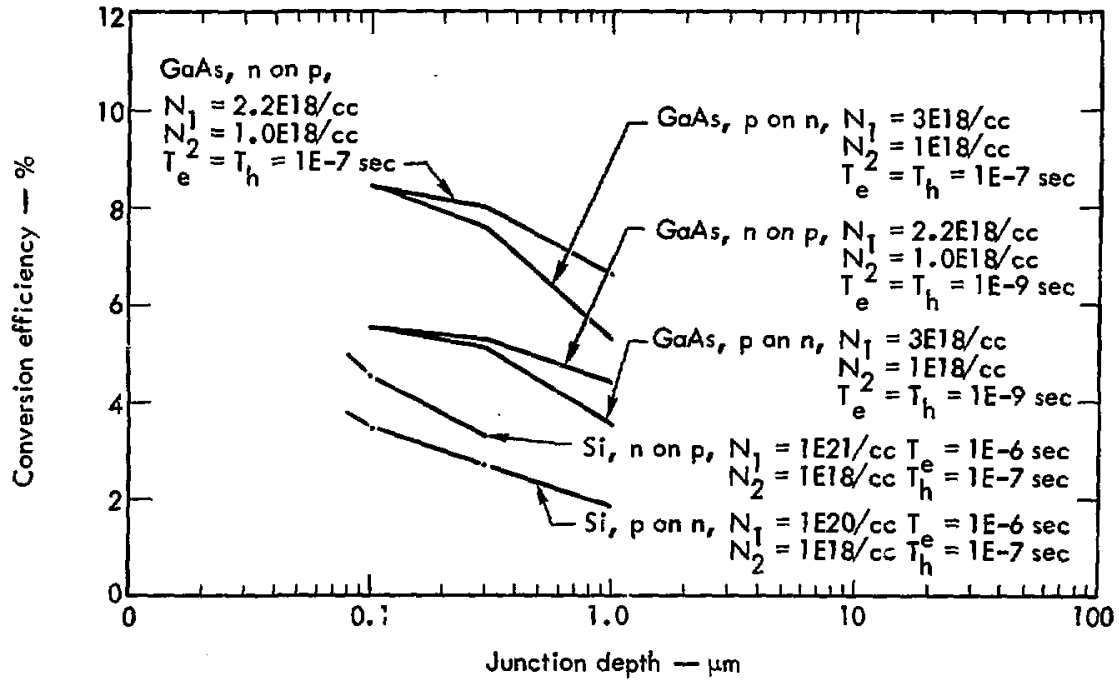

Fig. 20. Code-calculated conversion efficiency versus junction depth for GaAs and $\mathrm{S} i$ cells exposed to tritium-beta radiation of $32 \mu \mathrm{W} / \mathrm{cm}^{2}$ power. 
Figure 19 presents optimized efficiency versus junction-depth data for Si cell under $10 \mathrm{~mW} / \mathrm{cm}^{2} 1.06-\mu \mathrm{m}$ laser radiation. liallium arsenide cannot be used at this wavelength because of its transparency at $1.06 \mu \mathrm{m}$.

The energy of a 1.06- $\mu \mathrm{m}$ photon is greater than Si bandgap energy, however, absorption coefficient of $\mathrm{Si}$ is rather small this close to the bandgap energy. Consequently, there is no strong dependence on efficiency versus junction depth. Parameter data for this optimization are $S i, n$ on $p$, surface doping $10^{19} / \mathrm{cm}^{3}$, substrate duping $10^{16} / \mathrm{cm}^{3}, r_{e}=10^{-6} \mathrm{sec}$, and $\tau_{h}=10^{-7} \mathrm{sec}$.

Figure 20 shows optimized data for GaAs and $S i$ devfces to be used in the beta-voltaic mode, when exposed to an "infinitely thick" tritiun source (1.e., an excitation power of $32 \mu \mathrm{W} / \mathrm{cm}^{2}$ ). The n-on-p GaAs device is clearly the best choice, with $8.2 \%$ efficiency at a $0.1-\mu m$ junction depth, a surface dopant concentration of $2.2 \times 10^{18} / \mathrm{cm}^{3}$, a substrate dopant concentration of $1 \times 10^{18} / \mathrm{cm}^{3}$, and lifetimes of $\tau_{e}=\tau_{h}=10^{-7} \mathrm{sec}$. The Si p-on-n device is again the least efficient, in spite of the fact that dopant parameters are optimized.

\section{Experimental Verification of Model}

To verify the predictive capabilities of the code, we chose to measure the performance of experimental cells for which we had the best possible information on their materials and design parameters. We then fed this set of values into the code and compared the calculated performance data with the actual measurements. Current-voltage relationships (plots), maximum-power points, fill factors, and efficlency values were used as the performance criteria.

To obtain the necessary design and material data, a series of cells produced In-house with known process parameters were selected for the performance measurements. Following the trend for increasing efficiency, with decreasing junction depth, shallow-junction cells were fabricated using a borontrif luoride corona-discharge implantation technique. 5 The substrate-material propertles for these cells were known and the junction depth and doping profile of the Implanted player were obtained from Ion microprobe mass analysis data. 
The range of code effectiveness was tested by using a variety of excitation power sources and intensity levels for the experimental performance measurements. These were:

- Solar stmulation, using a quartz-iodine tungsten lamp at an intensity of $90 \mathrm{~mW} / \mathrm{cm}^{2}$

- "Cool white" fluorescent light at $0.2 \mathrm{mw} / \mathrm{cm}^{2}$

- Tritlum oeta radiation, using an infinitely thick tritium beta source $\left(32 \mathrm{\mu W} / \mathrm{cm}^{2}\right)$.

It should be noted that the cells produced were not provided with an antireflective coating, which led to a $32 \%$ reflection loss of the incident photons. This loss was taken into account, however, in the calculations. Electron reflection loss was neglected in the tritium test.

The efficiency calculated is the effective device efficiency (i.e., $10 \%$ of the area facing the incident energy is considered not active; that is, it is shaded by the electrode grid structure). The calculated values, therefore, can be compared directly with the measured values.

The results of comparing the calculated values with the measured data are shown in Figs. 21 through 23.

Figure 21 shows the data obtained under the simulated solar illumination. The specific spectrum of the simulator light was measured and fed into the code. (This spectrum differs sufficiently from true solar light that the values measured cannot be considered identicai to those obtained under true solar illumination. The plot in Fig. 21 shows very good agreement between the measured and calculated data.

Figure 22 shows measured and computed $I-V$ curves for a power leve1 obtained by illuminating a windowless room with fluorescent lamps. This level was $0.2 \mathrm{~mW} / \mathrm{cm}^{2}$, 450 times lower than the solar intensity used in Fig. 21. Figure 22 shows that, at this low light level, code calcuiations are in very good agreement with the experimental data.

Figure 23 compares computed and measured data for $32 \mu \mathrm{W} / \mathrm{cm}^{2}$ beta excitation from an infinitely thick tritium-beta source. A problem was encountered in this experiment as a result of the physical design of the test. The top and bottom surfaces, as well as the junction edge, were exposed to the beta radiation. Since the voltage of such a cell can be greatly affected by secondary emission differences at different prints on the cell, it was 


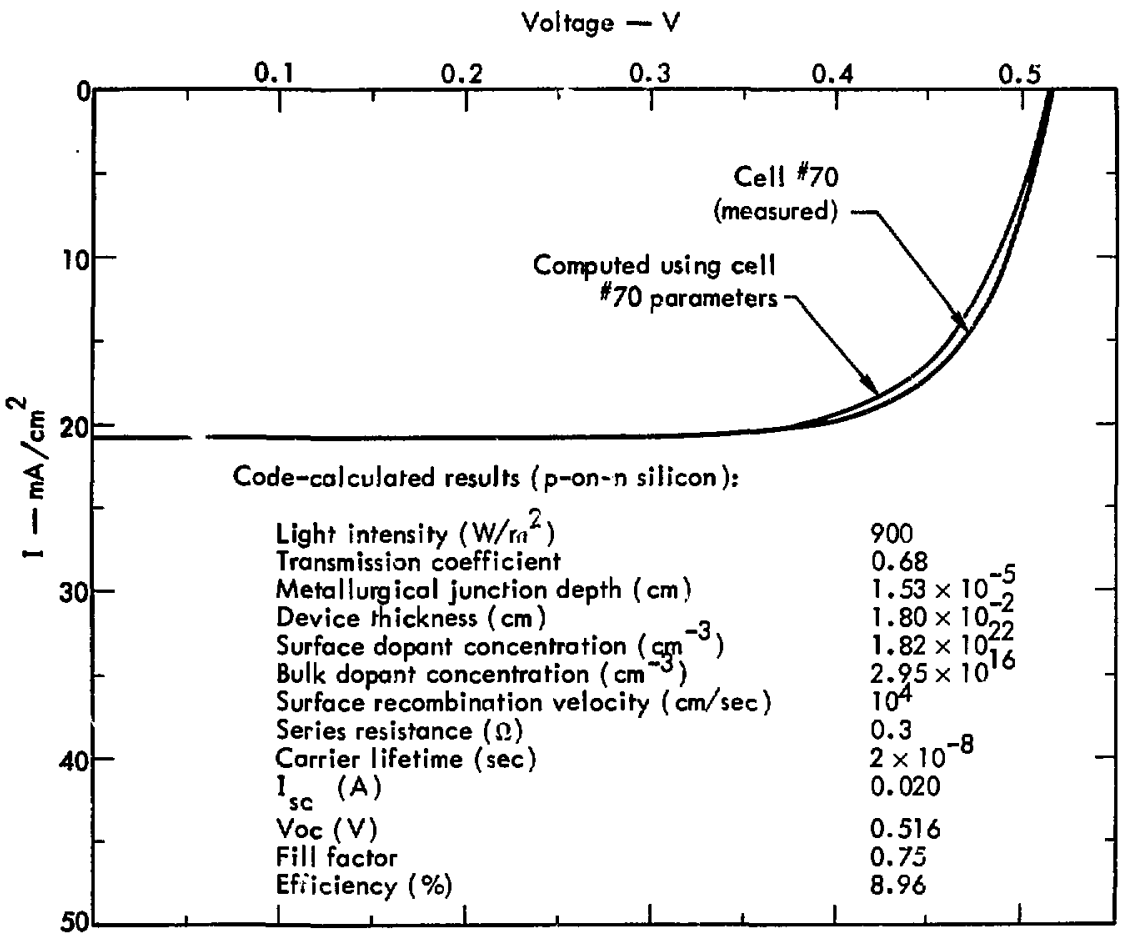

I'Ig. 21. Computed versus measured current-vritage curves (1ight source: or $\mathrm{mW} / \mathrm{cm}^{2}$ solar simulator).

found (and $i$ : to be expected) that the open-circuit voltage was not as high as it would be with a properly protected cell. There is good agreement, however, for the short-circuit current of one cell with two others showing lower sinort-circult currents than the computed value. But, In view of the experimental design, this is satisfactory agreement.

$A$ "olnt of Interest in making these measurements is that the shortcircult curr nts did not degrade during the first 150 days of exposure to tritfum betas. On the other hand, the open-circuit voltage (obtained as the net balance of betavoltaic and surface-irradiation effects varied strongly, dependfig upun whether the cell was operated in short-circuit or open-circult condition prior to a given measurement. 


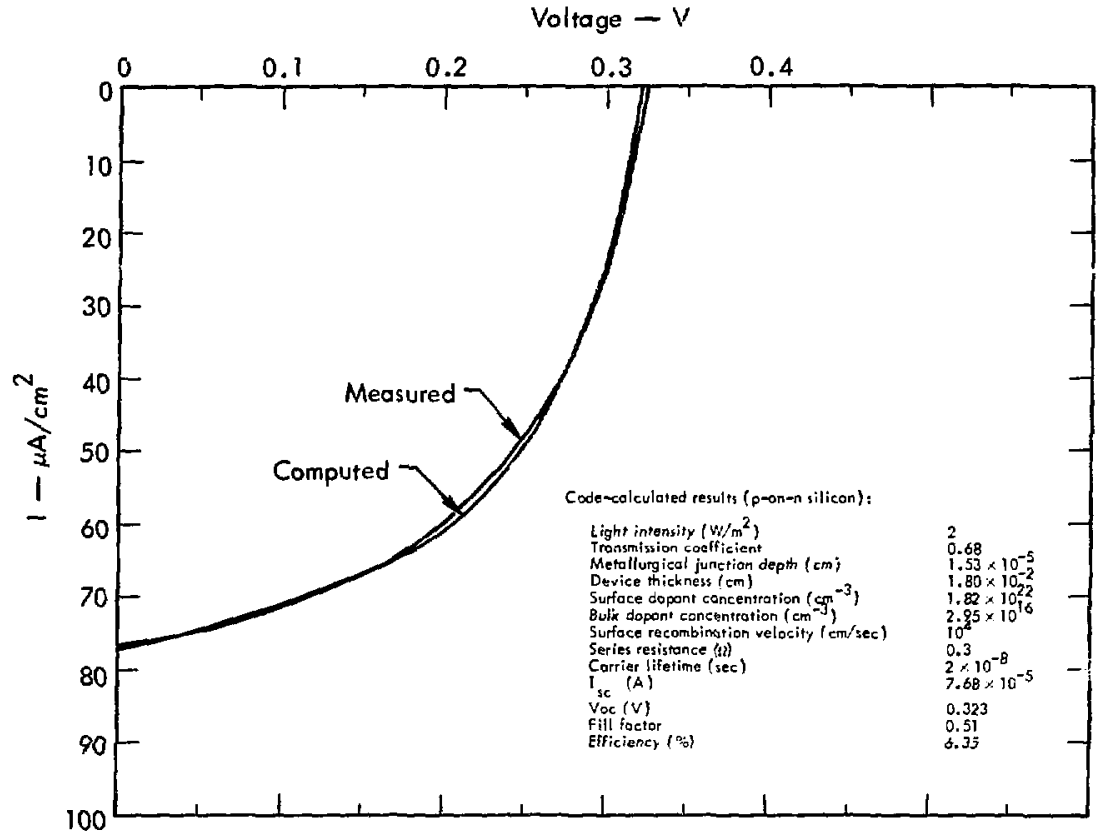

Fig. 22. Computed versus measured current-voltage curves (light source: $0.2 \mathrm{~mW} / \mathrm{cm}^{2}$ "cool-white" fluorescent room light).

\section{Discussion of Results}

Agreement between the msasured and calculated I-V curves for optical excitation is very good. However, not all parameters, partinularly those related to charge-transport characteristics, were based on actual measurements. Although the model computes clarge-transport properties for known doping levels and their gradients according to existing theory, certain assumptions, (e.g., lifetimes in the junction regions) have to be made. These assumptions determine the shape or the curve near the open-circuit voltage. One reason why the theoretical and the experimental curves show such excellent agreement is that carrier lifetimes in the depletion region were varied to provide a good $f i t$. These lifetime values are reasonable, but are somewhat 


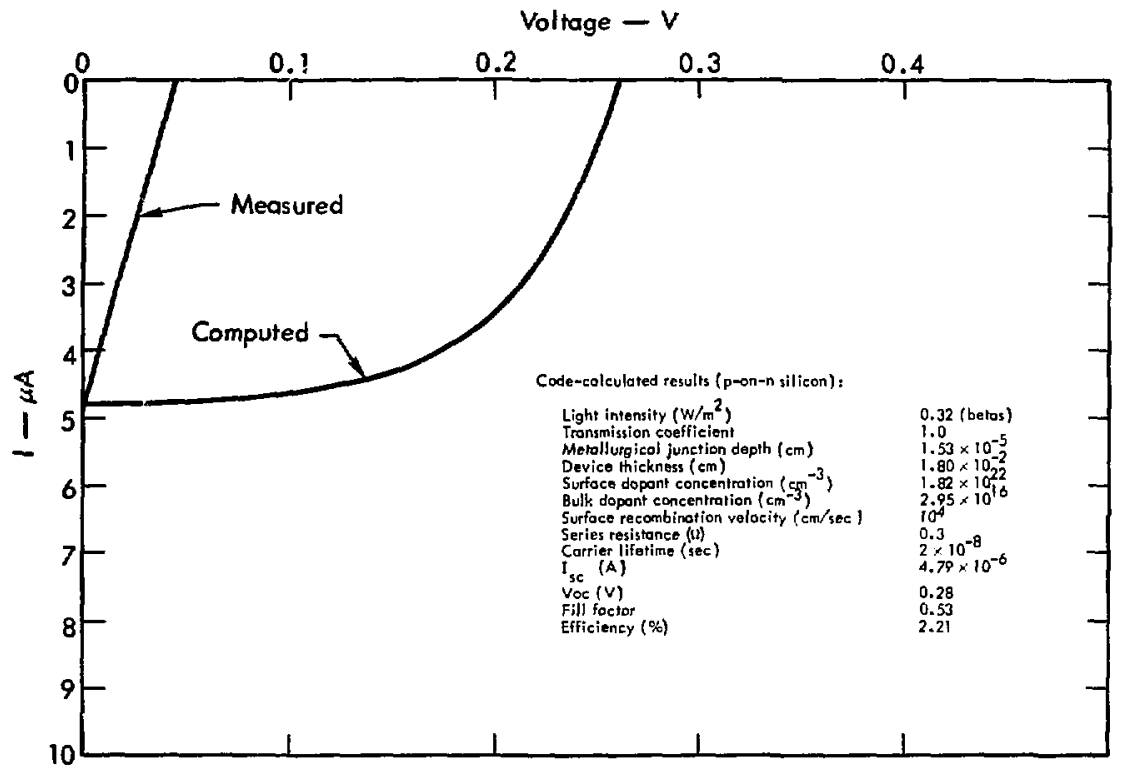

F1g. 23. Computed versus measured current-voltage curves (beta source: $32 \mu \mathrm{W} / \mathrm{cm}^{2}$ tritium).

lower than generally expected for good cells. There is no reason to believe, however, that these lifetimes are not the actual values in the measured device. As expected, varlations in depletion-layer lifetime had no influence on the short-circuit current.

\section{Conclusions}

We have developed a computer model for optimizing the effictency of beta- and photovoltalc devices, and have shown it to be in good agreement with experimental measurenents. We expect future work to be aimed at using this model to perform sensitivity analyses on device parameters and to fabricate optimized devices based on the results obtained. 


\section{Acknowledgment}

The authors wish to thank Robert Meisenheimer of the LLL Chemistry Department for providing the doping-profile data for the experimental cells used in this study.

\section{References}

1. R. Loevinger, Radiology 66, 55 (1956).

2. J. C. Irvin, Bel1 Syst. Tech. J. 41, 387 (1962).

3. J. G. Fossom, Computer-Aided Analysis of Silicon Solar Cells, Sandia Laboratories, Albuquerque, NM, Rept. SLA-74-0273 (1974).

4. D. Kendal1, Conf. on Phys. and Applic. of Lithium Diffused Stlicon, 1969 (NASA-Goddard Space Flight Center, 1969).

5. R. Wichner, Shallow-Junction Solar Ce1ls Fabricated by $\mathrm{BF}_{3}$ Corona Discharge, Lawrence Livermore Laboratory, Rept. UCRL-76814 (1975).

WOS/gw/w1 